IZA DP No. 6061

Add-on Pricing, Naive Consumers, and the Hidden Welfare Costs of Education

Michael Kosfeld

Ulrich Schüwer

October 2011 


\title{
Add-on Pricing, Naive Consumers, and the Hidden Welfare Costs of Education
}

\author{
Michael Kosfeld \\ Goethe University Frankfurt \\ and IZA \\ Ulrich Schüwer \\ Goethe University Frankfurt
}

\section{Discussion Paper No. 6061 \\ October 2011}

\author{
IZA \\ P.O. Box 7240 \\ 53072 Bonn \\ Germany \\ Phone: +49-228-3894-0 \\ Fax: +49-228-3894-180 \\ E-mail: iza@iza.org
}

\begin{abstract}
Any opinions expressed here are those of the author(s) and not those of IZA. Research published in this series may include views on policy, but the institute itself takes no institutional policy positions.

The Institute for the Study of Labor (IZA) in Bonn is a local and virtual international research center and a place of communication between science, politics and business. IZA is an independent nonprofit organization supported by Deutsche Post Foundation. The center is associated with the University of Bonn and offers a stimulating research environment through its international network, workshops and conferences, data service, project support, research visits and doctoral program. IZA engages in (i) original and internationally competitive research in all fields of labor economics, (ii) development of policy concepts, and (iii) dissemination of research results and concepts to the interested public.
\end{abstract}

IZA Discussion Papers often represent preliminary work and are circulated to encourage discussion. Citation of such a paper should account for its provisional character. A revised version may be available directly from the author. 


\section{ABSTRACT \\ Add-on Pricing, Naive Consumers, and the Hidden Welfare Costs of Education}

Previous research shows that firms shroud high add-on prices in competitive markets with naive consumers leading to inefficiency. We analyze the effects of regulatory intervention via educating naive consumers on equilibrium prices and welfare. Our model allows firms to shroud, unshroud, or partially unshroud add-on prices. Results show that consumer education may increase welfare; however, it may also decrease welfare if education is insufficient to alter the equilibrium information and pricing strategy of firms. Educating consumers may do more harm than good and should thus only be considered if the regulator is sufficiently well informed about consumer and firm behavior.

JEL Classification: D40, D80, L50

Keywords: bounded rationality, competition, regulation, welfare, consumer protection

Corresponding author:

Michael Kosfeld

Chair of Organization and Management

Goethe University Frankfurt

Grüneburgplatz 1

D-60323 Frankfurt/Main

Germany

E-mail: kosfeld@econ.uni-frankfurt.de

\footnotetext{
* We would like to thank Johan Almenberg, Roland Benabou and seminar participants at the 2010 AEA meeting, Atlanta, the 2010 Econometric Society World Congress, Shanghai, the 2010 EARIE meeting, Istanbul, and the 2010 Verein für Socialpolitik meeting, Kiel, for helpful comments.
} 


\section{Introduction}

If consumers are naive, firms will try to exploit it. Well-known examples are travelers who book a hotel room without thinking about the extra costs of add-ons such as parking or minibar, consumers who buy a printer without being aware of the costs of new printer cartridges, or bank customers who open a new deposit without considering the fees of offered investment funds. As shown by Gabaix and Laibson (2006) (henceforth GL), the equilibrium pricing strategy of firms in such situations may be to compete purely on the price of the base good (i.e., the hotel room, printer, or deposit) and to shroud any information about the price of the add-on (i.e., the minibar, printer cartridges, or investment funds). While the base good is priced below marginal costs the price of the add-on is above marginal costs. The consequences for consumers are twofold: First, sophisticated consumers who rationally expect that add-ons are overpriced will search for substitution possibilities leading to inefficiency if costs of substitution for the add-on exceed a firm's costs of production. For example, travelers may carry their own drinks, refill cartridges themselves, or build their own investment portfolios. Second, naive consumers who buy the add-on at the high price subsidize the low-priced base good and thereby sophisticated consumers, which raises consumer protection concerns. The question is if and how a regulator may intervene to increase economic welfare and to help and protect consumers in their decision making.

This paper analyzes the welfare effects of a simple and popular form of regulatory intervention: consumer education. ${ }^{1}$ Such education may come, for example, in the form of consumer protection campaigns that teach naive consumers to be aware of high-priced add-ons. It may also include "warning labels" that inform buyers about the possibility of shrouded product attributes. Intuition suggest that if such education comes at low costs and works, i.e., if consumers learn and become more sophisticated in their decision making, regulatory intervention will have only positive effects on consumer protection and welfare. In contrast, our results show that the effects can

\footnotetext{
${ }^{1}$ For example, the OECD, US, EU and UK launched several financial education initiatives over the last years. The OECD states that "financial education is necessary to ensure sufficient levels of investor and consumer protection as well as the smooth functioning, not only of financial markets, but also of the economy." (OECD, 2009, p. 3).
} 
actually be negative. Education entails hidden welfare costs that may render such intervention unfavorable. The reason is that education directly affects the behavior of some naive consumers but at the same time via the pricing strategy of firms indirectly also the outcomes of all other consumers. Whereas the first group is typically better off, our results show that the second group is typically worse off. If the costs of the latter outweigh the benefits of the former, educating naive consumers decreases economic welfare.

Our analysis is based on the model of GL; we extend their set-up, however, in two important ways. First, we assume that a regulator can educate a fraction of naive consumers before firms decide upon their pricing strategy. Second, besides shrouding the add-on or unshrouding, we allow firms to engage in partial unshrouding, which implies a particular form of price discrimination. The reason for considering price discrimination in our model is that it itself can increase market efficiency, in which case an intervention of the regulator may not be needed. Further, as we will see, there exist important interaction effects between regulatory intervention and price discrimination.

By price discrimination we consider the idea that firms may have information about consumers that correlates with consumers' sophistication in making decisions. For example, consumers with a degree in economics or finance are likely to make more sophisticated and better informed investment decisions than consumers who have no such educational background. Banks may use this information to classify consumers as either naive or sophisticated and fine-tune their product offers accordingly. However, the classification of consumers is unlikely to be perfect. We hence allow for the possibility that firms erroneously classify a naive consumer as sophisticated or vice versa.

Our results show that price discrimination is a symmetric equilibrium if and only if firms classify consumers sufficiently well and the share of naive consumers is intermediate. Firms shroud the add-on price if there are many naive consumers and unshroud prices if the fraction of naive consumers is low. As intuition suggests, price discrimination increases welfare relatively to a shrouded prices equilibrium. However, it decreases welfare relatively to an unshrouded prices equilibrium. Since markets 
may remain inefficient and some consumers continue to pay high prices, regulatory intervention remains on the agenda.

If the regulator intervenes by educating consumers, the share of sophisticated consumers increases by some positive fraction. Firms react to this by adjusting prices to a new equilibrium. We show that economic welfare increases if the rise in sophisticated consumers is sufficiently large such that firms unshroud prices in the new equilibrium. In all other cases welfare effects are or can be negative. Ex-ante naive consumers who become educated always benefit from the intervention as they make better consumption decisions. However, naive consumers who remain naive as well as sophisticated consumers typically lose. Since these consumers are unable to improve their decision about the add-on, the change in consumption costs in their case depends on the price of the base good which, as a consequence of the intervention, increases.

The main message of our paper is that education which is good for the single consumer may be bad for the group of consumers as a whole. Due to a feedback on prices educating some consumers may entail hidden costs for other consumers, leading to increased prices and a reduction in overall welfare. Education is welfare improving, however, if sufficiently many naive consumers react. Unfortunately, evidence suggests that chances do not look very bright with this respect. Choi, Laibson and Madrian (2010), for example, show in an investment experiment with high monetary incentives that more than 80 percent of the participants fail to take into account the, in part, substantial fees of investment products even when these fees are made transparent and salient. ${ }^{2}$ In the light of these results, regulators are advised to take into account that the success of educating naive consumers is likely to be moderate to low. Consequently, intervention may be harmful and a regulator's courses of action are plagued with pitfalls. For example, increasing the success rate of education without upsetting the underlying type of market equilibrium can make things worse.

\footnotetext{
${ }^{2}$ Other studies show that financial counseling or mandatory disclosure do little to improve the decisions of consumers in the mortgage market (Agarwal et al., 2009; Lacko and Pappalardo, 2010). Bhattacharya et al. (2011) document that only few retail investors are interested in free and independent investment advice, and if they obtain it, hardly follow the advice. Willis (2011) highlights that effective education would be extremely costly, and suggests that the regulator should explore other tools to increase household financial welfare. For a literature review on financial education, see De Meza, Irlenbusch and Reyniers (2008).
} 
Likewise, regulatory intervention without knowing whether firms are able to engage in price discrimination or not yields effects that go in any direction. In particular, it may be that educating consumers increases welfare if firms are able to engage in price discrimination but decreases welfare if no such possibility exists.

While regulatory intervention by education may thus be unsuitable to improve welfare and consumer protection, we briefly discuss three alternatives for the regulator. These alternative interventions are based on direct subsidies to consumers or firms, promoting particular consumer or information and pricing behavior, respectively. Our results show that direct subsidies to consumers have zero effect on welfare, but subsidizing firms can actually be effective. On the one hand, the regulator can subsidizes firms that unshroud and sell the add-on at a low price to all consumers, which prevents that sophisticated consumers substitute away and improves welfare. On the other hand, the regulator can subsidize firms that sell the add-on to sophisticated consumers only. In particular, subsidized firms advertise the add-on at an exceptionally low price and the base good at an above market price, such that sophisticated consumers buy at subsidized firms and naive consumers (who only consider the base good price) buy at other firms. ${ }^{3}$ While both strategies achieve the same welfare improvement, they differ in the required volume of subsidies. The former strategy requires lower subsidies if and only if the share of naive consumers is not too large. The discussion shows that subsidizing firms can be a good alternative strategy for improving welfare, but similar to the case of consumer education, the choice of the optimal strategy depends on a good understanding of consumer and firm behavior.

Our paper contributes to the growing literature analyzing the role of consumer bounded rationality in industrial organization. The literature shows that consumers' bounded rationality can lead to enhanced exploitation of consumers and create an inefficiency, which is also well documented empirically for a large variety of markets. ${ }^{4}$ In light of the 2007-2008 financial crisis, especially the mortgage market and the

\footnotetext{
${ }^{3}$ Note that restricting subsidies to firms that serve naive consumers only is impossible as sophisticated consumers will always be attracted by the subsidized pricing policy.

${ }^{4}$ For an overview on bounded rationality and industrial organization, see Ellison (2006) and Spiegler (2011). As regards the interaction between competition and consumer policy, see also Armstrong (2008). For an overview on empirical studies in several fields of the literature, see DellaVigna (2009).
} 
retail investment market got a lot of attention from policymakers and researchers. Several studies show that some borrowers' poor understanding of the mortgage market leads to excessive charges and inefficiency (see, e.g., Agarwal et al., 2009; Woodward and Hall, 2010). Further, less well educated individual investors are more likely to make investment mistakes (Calvet, Campbell and Sodini, 2009). Retail investors pay, on average, an 8 percent premium for popular structured equity products relative to the fair market value of these securities (Henderson and Pearson, 2011). Carlin (2009) argues that firms in retail financial markets may add complexity to their price structures in order to prevent that consumers become informed and purchase the product at a lower price.

Studies that explore if regulatory intervention can fix market frictions due to consumers' bounded rationality come to mixed results. ${ }^{5}$ Regulatory intervention via educating consumers or creating transparency is largely uncontroversial (see, e.g., Jolls and Sunstein, 2006). However, recent research also points to potential negative effects. For example, Kamenica, Mullainathan and Thaler (2011) show that prices can increase when consumers make better decisions for themselves. In their model, the consumer loss from higher prices exactly offsets the consumer gain from better decisions, leaving economic welfare unchanged. Glaeser and Ujhelyi (2010) analyze the case of regulating misleading advertising, which may exist in the form of shrouded add-ons. They show that misinformation may be a good thing for welfare if oligopoly pricing leads to underconsumption of a product and misinformation increases consumption. Then, regulatory intervention by educating consumers ("counter-advertising") or other forms of regulatory intervention can have negative welfare effects.

Our analysis differs in several aspects. In particular, different from Kamenica, Mullainathan and Thaler (2011), in our model, better decisions by consumers involve costly substitution behavior if firms decide to shroud add-on prices. Thus, welfare is not constant but depends on the behavior of consumers and firms. In contrast to

\footnotetext{
${ }^{5}$ For example, Armstrong, Vickers and Zhou (2009) show that consumer protection policies such as price caps have possibly undesirable effects if it leads to a weakening of competitive pressures. Spiegler $(2006 a, b)$ analyzes markets where consumers cannot observe the price or quality of a product and suggests that there can be a role for regulation to create transparency.
} 
Glaeser and Ujhelyi (2010), misinformation in our model leads to a decrease rather than to an increase in consumption.

The paper is organized as follows. Section 2 presents the main model. Section 3 calculates market equilibria with and without regulatory intervention. Section 4 contains the main results regarding economic welfare and consumer costs. Section 5 briefly discusses alternatives strategies for regulatory intervention. Finally, section 6 concludes.

\section{Model}

Our model follows the one of GL. There is finite number of firms that produce a homogeneous base good and add-on, both at zero marginal cost. The add-on is always avoidable for informed consumers, in contrast to unavoidable surcharges which are not considered in our model. The mass of consumers is normalized to 1 . Consumers are of two types: A fraction $\alpha \in(0,1)$ of consumers are naive (myopic, in the language of GL), they only take the price of the base good into consideration when deciding to purchase a good. The remaining fraction $1-\alpha$ are sophisticated and consider both the price of the base good and the price of the add-on. In case firms do not advertise the add-on, sophisticated consumers form Bayesian posteriors about the add-on price.

Let $p$ denote the price of the base good and $\hat{p}$ the price of the add-on. We focus on symmetric price equilibria throughout the paper and hence omit firm-subscripts whenever doing so causes no confusion. As in GL, firms decide to shroud or unshroud add-on prices when consumers make a buying decision about the base good. Both activities are free. Shrouding means that a firms suppresses information about the price of the add-on. Unshrouding means that firms advertise the price of the addon broadly. If a firm unshrouds, all sophisticated consumers as well as a fraction $\lambda_{F} \in[0,1)$ of naive consumers become informed about the price of the add-on and take it into account when purchasing the good. The latter group of informed naive consumers is the result of the educational effect of a firm's unshrouding activity. These consumers are initially naive but behave just like sophisticated consumers once a firm unshrouds. The remaining fraction $1-\lambda_{F}$ of naive consumers do not take the 
add-on price into consideration even when firms unshroud. This group of uninformed naive consumers is either not receptive or not able to use the relevant information.

Consumers have a maximum willingness to pay for the add-on $\bar{p}$, which sets an upper bound for the price $\hat{p}$, i.e., $\hat{p} \leq \bar{p}$. In addition, consumers who are informed about or expect high add-on prices, can avoid the add-on by substituting away at cost $e<\bar{p}$. Hence, firms can charge a maximum add-on price $\bar{p}$ from uninformed naive consumers and $e$ from sophisticated and informed naive consumers.

The first innovation in our model is that, in addition to always (un)shrouding addon prices, firms can make special offers to consumers who they classify as naive or sophisticated. This strategy results in a particular form of price discrimination. We assume that firms can use available personal information such as education, employment, etc. to classify consumers. Firms unshroud add-on prices towards consumers whom they classify as sophisticated because they assume that these consumers otherwise form Bayesian posteriors about the add-on price and substitute away. The advertised add-on price for these consumers, $\hat{p}_{S}$, cannot exceed $e$, the substitution costs of sophisticated consumers. Furthermore, firms shroud information towards consumers classified as naive. The add-on price for these consumers, $\hat{p}_{N}$, is at most $\bar{p}$, the reservation price of uninformed naive consumers.

To illustrate, consider the following example. Banks offer a deposit of securities as a base good and different investment funds as an add-on. Suppose banks know the educational background of their costumers and use this information to classify them as naive or sophisticated consumers. They can then advertise an investment fund with low annual fees, e.g. an exchange-traded fund (ETF), only to consumers with a degree in finance. All other consumers are offered actively managed investment funds with high annual fees.

We allow for the possibility that firms make mistakes when classifying consumers. With probability $1-\beta$, firms erroneously classify a sophisticated consumer as naive. Further, with probability $1-\gamma$, firms erroneously classify a naive consumer as sophisticated. Intuitively, $\beta, \gamma \in[0,1]$ model the accuracy of firms' consumer classification. The closer these parameter are to 1 , the better firms can identify a consumer's true type. As long as $\beta$ and $\gamma$ are strictly below 1, misclassification implies that firms un- 
shroud the low add-on price $\hat{p}_{S}$ towards a non-zero fraction of naive consumers while a non-zero fraction of sophisticated consumers will not receive the low-price offer. In equilibrium, the latter group will therefore substitute away because they expect high prices while the former group will earn a rent. ${ }^{6}$

Considering our example, we assume that a fraction $1-\gamma$ of naive consumers have a degree in finance and are hence erroneously classified as sophisticated. These naive consumers then profit from the misclassification because they are offered the ETF with low annual fees, although they would have bought the more expensive, actively managed fund, as well. Further, a fraction $1-\beta$ of sophisticated consumers do not have a finance degree and are therefore erroneously classified as naive. These consumers build their own diversified portfolio (i.e., substitute away) at cost $e$, because they do not get any information about the low-priced add-on and expect that the bank offers an actively managed fund with high annual fees.

The second innovation in our model is that we allow for regulatory intervention. Before firms decide on their information and pricing strategy, we assume that the regulator can educate a fraction $\lambda_{R} \in[0,1)$ of naive consumers about the relevance of add-on prices. Such intervention increases the share of informed consumers in the population prior to any potential educational effect of a firm's unshrouding strategy from $1-\alpha$ to $1-\left(1-\lambda_{R}\right) \alpha .^{7}$ To abstract from implementation costs we assume that educating consumers is free.

Following GL we analyze price competition by modeling the demand at firm $i$ as the probability $D\left(x_{i}\right)$ that a consumer purchases a product at that firm. The probability depends on $x_{i}$, which denotes the anticipated net surplus from purchasing at firm $i$ less the anticipated net surplus from purchasing at the best alternative firm. Formally, the demand function can be derived from a random-utility model, where individual $a$ consuming product $i$ has utility $U_{a i}=v-p_{i}+\varepsilon_{a i}$, with $v$ and $p_{i}$ denoting the quality and the price of the product, respectively, and $\varepsilon_{a i}$ denoting a random

\footnotetext{
${ }^{6}$ Below we show that a necessary condition for price discrimination to be an equilibrium is that $\beta>1-\gamma$.

${ }^{7}$ For simplicity, we assume that the educational effect of a firm's unshrouding strategy and regulatory intervention are independent, i.e., $\lambda_{F}$ is unaffected by the regulator's decision to educate.
} 
idiosyncratic preference component that is i.i.d. across consumers and products. ${ }^{8}$

Since firms sell homogenous goods, the anticipated net surplus of uninformed naive consumers who do not take the add-on price into consideration equals

$$
x_{i}=-p_{i}+p^{*},
$$

where $p_{i}$ and $p^{*}$ denote the price of the base good at firm $i$ and the price of the base good at the best alternative firm, respectively. For a sophisticated (and an informed naive) consumer, who takes both the price of the base good and the price of the add-on into account, anticipated net surplus equals

$$
x_{i}=-p_{i}-\min \left\{E \hat{p}_{i}, e\right\}+p^{*}+\min \left\{E \hat{p}^{*}, e\right\},
$$

where $E \hat{p}_{i}$ and $E \hat{p}^{*}$ represent the expected add-on price at firm $i$ and the expected add-on price at the best alternative firm, respectively. If information is unshrouded, $E \hat{p}_{i}=\hat{p}_{i}$ and $E \hat{p}^{*}=\hat{p}^{*}$.

The timing of decisions in our model is as follows:

\section{Period 0}

- The regulator decides whether to educate a fraction $\lambda_{R}$ of naive consumers about the relevance of add-ons.

\section{Period 1}

- Firms choose their information and pricing strategy.

* In case of shrouding, firms suppress information about the add-on. They pick a price for the base good, $p$, and a price for the add-on, $\hat{p}$.

* In case of unshrouding, firms advertise the add-on price towards all consumers. Unshrouding makes sophisticated consumers and a fraction $\lambda_{F}$ of naive consumers aware of the add-on price. Firms also pick prices $p$ and $\hat{p}$.

\footnotetext{
${ }^{8}$ We refer to GL, p. $532-533$ for details. See also Anderson, de Palma and Thisse (1992) for a general introduction into discrete choice models of price competition.
} 
* In case of price discrimination, firms shroud add-on prices towards consumers classified as naive and unshroud add-on prices towards consumers classified as sophisticated. Firms pick a price for the base good, $p$, and prices for the add-on, $\hat{p}_{N}$ and $\hat{p}_{S}$, for consumers classified as naive and sophisticated, respectively.

\section{Period 2}

- Informed consumers (sophisticated and informed naive) always take the price of the add-on into consideration. Sophisticated consumers who do not receive any information about the add-on (because firms shroud or they are erroneously classified as naive), form Bayesian posteriors about the add-on price.

- Uninformed naive consumers do not consider the add-on for their buying decision.

- Consumers choose a firm.

- Informed consumers can decide to substitute away at cost $e .^{9}$

\section{Period 3}

- Consumers observe the add-on price (if they have not done so already).

- All consumers buy the base good.

- Uninformed consumers buy the add-on if the price is at most their reservation price $\bar{p}$.

- Informed consumers buy the add-on if they have not already substituted away in period 2 .

\section{Price equilibria}

We first analyze symmetric price equilibria without regulatory intervention. GL show that there exist two symmetric equilibria in their set-up: a shrouded prices and an

\footnotetext{
${ }^{9}$ Like GL we assume that substitution costs occur prior to the purchase of the base good.
} 
unshrouded prices equilibrium. The existence of these equilibria depends on the share of naive consumers in the population, the substitution costs and the upper bound for the add-on price. If the share of naive consumers is relatively large, i.e. $\alpha>\frac{e}{\bar{p}}$, the shrouded prices equilibrium exists. If there are relatively few naive consumers, i.e. $\alpha<\frac{e}{\bar{p}}$, the unshrouded prices equilibrium exists. We extend their result by showing that firms' possibility to classify consumers as naive or sophisticated changes the thresholds above, and that price discrimination can become a third equilibrium if the share of naive consumers is intermediate.

Proposition 1 (Price Equilibria Without Regulatory Intervention). Let

$$
\alpha^{\dagger}=\min \left(\frac{e}{\bar{p}}, \frac{e(1-\beta)}{e(1-\beta)+(\bar{p}-e) \gamma}\right)
$$

and

$$
\alpha^{\ddagger}=\max \left(\frac{e}{\bar{p}}, \frac{e \beta}{e \beta+(\bar{p}-e)(1-\gamma)}\right) .
$$

If $\alpha<\alpha^{\dagger}$, there exists a symmetric equilibrium, in which firms unshroud the add-on price and set $\hat{p}=e$ (unshrouded prices equilibrium). If $\alpha^{\dagger}<\alpha<\alpha^{\ddagger}$, there exists a symmetric equilibrium, in which firms engage in price discrimination with $\hat{p}_{S}=e$ and $\hat{p}_{N}=\bar{p}$ (price discrimination equilibrium). If $\alpha^{\ddagger}<\alpha$, there exists a symmetric equilibrium, in which firms shroud the add-on price and set $\hat{p}=\bar{p}$ (shrouded prices equilibrium).

All proofs are in the appendix.

Proposition 1 is illustrated in Figure 1. If the share of naive consumers is small $\left(\alpha<\alpha^{\dagger}\right)$, it is optimal to sell the add-on to every consumer. As sophisticated consumers substitute away if they observe (or expect) add-on prices larger than $e$, firms optimally set a price $\hat{p}=e$ and unshroud. From the first-order condition $\left(p+\hat{p}=\frac{D(0)}{D^{\prime}(0)}=\mu\right)$ it follows that the price of the base good is equal to $\mu-e$ in the unshrouded prices equilibrium.

If the share of naive consumers is intermediate $\left(\alpha^{\dagger}<\alpha<\alpha^{\ddagger}\right)$, price discrimination is an equilibrium strategy. A necessary condition is that $\alpha^{\dagger}<\alpha^{\ddagger}$, which holds if and only if $\beta>1-\gamma$, i.e., errors from misclassification are small. Firms choose the 


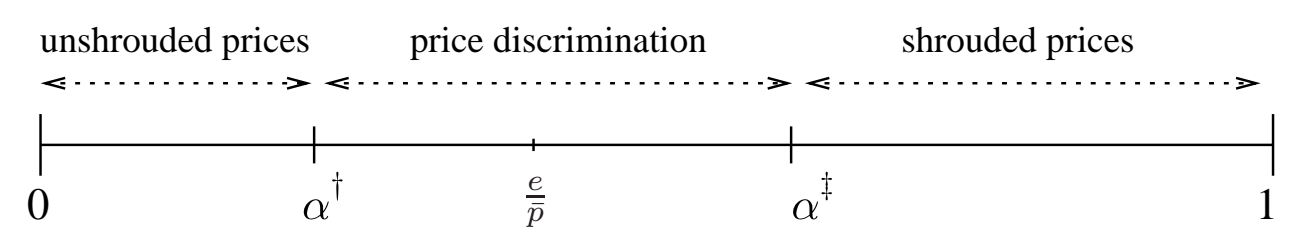

Figure 1: Price Equilibria Without Regulatory Intervention

highest possible add-on price $\hat{p}_{N}=\bar{p}$ as a standard, which they shroud, and make special offers $\hat{p}_{S}=e$ to consumers who they classify as sophisticated. If $\beta<1$, some sophisticated consumers are misclassified and do not receive the special offer. These consumers see that firms shroud, conclude that $E \hat{p}=\bar{p}$ and hence substitute away. Firms accept this as the share of naive consumers is sufficiently large such that it pays to shroud the high add-on price. On the other hand, if $\gamma<1$, there are some naive consumers who buy the add-on at a price $\hat{p}_{S}=e$ that is strictly below their reservation price $\bar{p}$. Firms accept this as well, as the share of naive consumers is not large enough for it to pay to ignore sophisticated consumers and shroud the add-on completely. Note that price discrimination yields higher revenue for firms on the add-on. However, competition on the base-good market forces firms to pass this extra revenue to consumers in the form of lower base-good prices. In the price discrimination equilibrium, the price of the base good is therefore lower than in the unshrouded prices equilibrium. From the first-order condition we see that it is equal to $\mu-\alpha \gamma \bar{p}-e(\alpha(1-\gamma)+(1-\alpha) \beta)$.

Finally, a shrouded prices equilibrium exists, if the share of naive consumers is large $\left(\alpha>\alpha^{\ddagger}\right)$. In this case, firms sell the add-on at the highest possible price $\hat{p}=\bar{p}$ to naive consumers only. Information is shrouded because unshrouding decreases the fraction of uninformed consumers. Sophisticated consumers observe that firms shroud, rationally expect that $E \hat{p}=\bar{p}$ and hence substitute away. Again, all extra revenue on the add-on is competed away on the base-good market, leading to a price for the base good equal to $\mu-\alpha \bar{p}$.

Table 1 summarizes prices, consumer costs and welfare for the different price equilibria. 
Table 1: Prices, Consumer Costs and Welfare

\begin{tabular}{|c|c|c|c|c|c|}
\hline Unshrouded prices & & $\begin{array}{l}\text { Uninformed } \\
\text { Naive }\end{array}$ & $\begin{array}{l}\text { Informed } \\
\text { Naive }\end{array}$ & $\begin{array}{c}\text { Informed } \\
\text { Sophisticated }\end{array}$ & $\begin{array}{c}\text { Uninformed } \\
\text { Sophisticated }\end{array}$ \\
\hline Base good & \multicolumn{5}{|c|}{$\mu-e$} \\
\hline Add-on & \multirow{2}{*}{\multicolumn{5}{|c|}{$e$}} \\
\hline Substitution & & & & & \\
\hline Share of consumers & & $\left(1-\lambda_{F}\right) \alpha$ & $\lambda_{F} \alpha$ & $1-\alpha$ & \\
\hline Welfare loss & \multicolumn{5}{|c|}{0} \\
\hline Price discrimination & & $\begin{array}{l}\text { Uninformed } \\
\text { Naive }\end{array}$ & $\begin{array}{l}\text { Informed } \\
\text { Naive }\end{array}$ & $\begin{array}{c}\text { Informed } \\
\text { Sophisticated }\end{array}$ & $\begin{array}{c}\text { Uninformed } \\
\text { Sophisticated }\end{array}$ \\
\hline Base good & \multicolumn{5}{|c|}{$\mu-\alpha \gamma \bar{p}-e(\alpha(1-\gamma)+(1-\alpha) \beta)$} \\
\hline Add-on & $\bar{p}$ & $e$ & e & $e$ & \\
\hline Substitution & & & & & \\
\hline Share of consumers & $\gamma \alpha$ & $\left(1-\lambda_{F}\right)(1-\gamma) \alpha$ & $\lambda_{F}(1-\gamma) \alpha$ & $\beta(1-\alpha)$ & $(1-\beta)(1-\alpha)$ \\
\hline Welfare loss & \multicolumn{5}{|c|}{$(1-\beta)(1-\alpha) e$} \\
\hline Shrouded nrices & & Uninformed & Informed & Informed & Uninformed \\
\hline Base good & \multicolumn{5}{|c|}{$\mu-\alpha \bar{p}$} \\
\hline Add-on & & $\bar{p}$ & & & \\
\hline Substitution & & & & & $e$ \\
\hline Share of consumers & & $\alpha$ & & & $1-\alpha$ \\
\hline
\end{tabular}

As already mentioned, a necessary condition for price discrimination to be an equilibrium is that the interval $\left[\alpha^{\dagger}, \alpha^{\ddagger}\right]$ exists, which is equivalent to $\beta>1-\gamma$. If this condition is not fulfilled, Proposition 1 is equivalent to the main result in GL, as the following Corollary 1 summarizes.

Corollary 1 (No Price Discrimination, Gabaix and Laibson, 2006). Suppose that $\beta \leq 1-\gamma$. This implies that $a^{\dagger}=\alpha^{\ddagger}=\frac{e}{\bar{p}}$. There exist an unshrouded prices equilibrium if $\alpha<\frac{e}{\bar{p}}$ and a shrouded prices equilibrium if $\alpha>\frac{e}{\bar{p}}$.

On the other hand, if errors are relatively small and sophisticated consumers can be classified perfectly $(1-\gamma<\beta=1)$, price discrimination always dominates unshrouding. In consequence, the unshrouded prices equilibrium no longer exists. 
Corollary 2 (No Unshrouding). Suppose that $1-\gamma<\beta=1$. This implies that $\alpha^{\dagger}=0$ and $\alpha^{\ddagger}=\frac{e}{e+(\bar{p}-e)(1-\gamma)}$. There exist a price discrimination equilibrium if $\alpha<\alpha^{\ddagger}$ and $a$ shrouded prices equilibrium if $\alpha>\alpha^{\ddagger}$.

Similarly, if errors are small and uninformed naive consumers can be classified perfectly $(1-\beta<\gamma=1)$, price discrimination dominates shrouding. Thus, the shrouded prices equilibrium no longer exists.

Corollary 3 (No Shrouding). Suppose that $1-\beta<\gamma=1$. This implies that $\alpha^{\dagger}=$ $\frac{e(1-\beta)}{e(1-\beta)+(\bar{p}-e)}$ and $\alpha^{\ddagger}=1$. There only exist a unshrouded prices equilibrium if $\alpha<\alpha^{\dagger}$ and a price discrimination equilibrium if $\alpha>\alpha^{\dagger}$.

Together Corollary 2 and 3 imply that if both consumer types are classified perfectly $(\beta=\gamma=1)$, neither shrouding nor unshrouding can be equilibrium, and only the price discrimination equilibrium remains. ${ }^{10}$

Suppose now that the regulator decides to educate naive consumers about the relevance of potentially high add-on prices. Formally, this implies that a fraction $\lambda_{R} \in$ $[0,1)$ of ex-ante naive consumers become sophisticated, i.e., the share of sophisticated consumers rises from $1-\alpha$ to $1-\left(1-\lambda_{R}\right) \alpha$. The effect on price equilibria of this intervention is that equilibrium thresholds specified in Proposition 1 shift to the right.

Proposition 2 (Price Equilibria With Regulatory Intervention). Suppose the regulator intervenes by increasing the share of sophisticated consumers by $\lambda_{R} \alpha$. Let $\alpha^{\S}=\frac{1}{1-\lambda_{R}} \alpha^{\dagger}$ and $\alpha^{\sharp}=\frac{1}{1-\lambda_{R}} \alpha^{\ddagger}$. An unshrouded prices equilibrium exists if $\alpha<\alpha^{\S}$, a price discrimination equilibrium exists if $\alpha^{\S}<\alpha<\alpha^{\sharp}$, and a shrouded prices equilibrium exists if $\alpha^{\sharp}<\alpha$.

Figure 2 illustrates the effect of regulatory intervention on equilibrium thresholds and corresponding equilibrium intervals. Generally, both the area where firms unshroud prices and the area where firms price discriminate in equilibrium increases,

\footnotetext{
${ }^{10}$ There exists a non-empty interval to the right of $\alpha^{\dagger}$, in which both the price discrimination and the unshrouded prices equilibrium co-exist. A similar interval exists to the right of $\alpha^{\ddagger}$, in which the price discrimination and the shrouded prices equilibrium co-exist. The size of these intervals depend on $\lambda_{F}$ (see the proof of Proposition 1 for details). Since the multiplicity of equilibria is not immediately relevant for the results in our model, we do not consider this issue any further in the following.
} 
whereas the area, in which firms shroud prices becomes smaller. The size of the right shift depends on $\lambda_{R}$. The more naive consumers are affected by the regulation the greater is the effect on firms' equilibrium behavior and corresponding market outcomes.

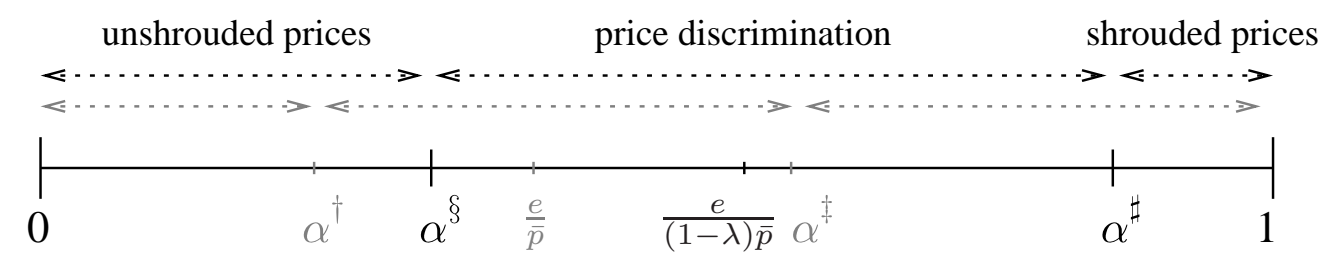

Figure 2: Price Equilibria With (And Without) Regulatory Intervention

In the next section, we analyze in detail the impact of regulatory intervention on equilibrium prices and economic welfare. The analysis follows an equilibrium approach, i.e., we assume that firms in the market adjust to the new equilibrium after intervention and compare market outcomes to those that would realize in equilibrium if the regulator did not intervene.

\section{Welfare effects and consumer costs}

There are two potential reasons why the regulator may decide to intervene in the given market. The first reason is that market outcomes may be inefficient, because some consumers - the sophisticated - exert costly effort to substitute add-ons that can costlessly be produced by firms. This inefficiency arises whenever firms shroud the add-on or price discriminate but do not reach all sophisticated consumers. Economic welfare is fully captured by consumer costs in our model because firm equilibrium profit is constant. In particular, as firms produce at zero marginal cost, firm profit per consumer is determined by the average total price of the base good and the addon. In equilibrium, this price is determined by the demand function $D$ and is equal to $\mu=\frac{D(0)}{D^{\prime}(0)}$ in any equilibrium.

The second reason for intervention is that some consumers - the naive - pay too much for the add-on and thus serve as a cash cow which subsidizes low base 
good prices for sophisticated consumers. Again, this may happen when firms either shroud the add-on or choose (imperfect) price discrimination. Note that total costs of consumption of an ex-ante naive consumer depend on whether the consumer becomes informed about add-ons or stays uninformed as firms (partially) unshroud or the regulator educates, respectively. We interpret the fraction of naive consumers who become informed as the probability for an ex-ante naive consumer to become informed and calculate expected costs of consumption of an ex-ante naive consumer.

As a reference point for the analysis, consider the extreme cases that all consumers are sophisticated or all consumers are naive. In the first case, the profit maximizing pricing strategy of firms is to compete on both the price of the base good and the price of the add-on. The bundle of both products will be offered at cost-reflective prices to all consumers who have no incentive to substitute away. In the second case, the profit maximizing pricing strategy of firms is to compete purely on the price of the base good and to charge the reservation price of consumers for the add-on. Again, the bundle of both products will be offered at cost-reflective prices to all consumers because the firms' profits from high add-on prices get competed away on the base good. Such a price equilibrium represent the so-called loss-leader pricing (Lal and Matutes, 1994). Thus, the consumer harm is limited to the inefficiency caused by the departure of prices from costs on a product-by-product basis, e.g., consumers may replace the base good too early. It is generally argued that this welfare loss is relatively small. In sum, both the situation where all consumers are sophisticated and the situation where all consumers are naive generally do not require regulatory intervention. Welfare and consumer protection issues arise because consumer are heterogenous.

We begin the analysis by summarizing the effect of price discrimination on welfare, i.e., we calculate and compare the realized welfare loss with and without the possibility for firms to price discriminate.

Proposition 3 (Welfare Effects of Price Discrimination). Price discrimination strictly increases economic welfare relative to a shrouded prices equilibrium $\left(\frac{e}{\bar{p}}<\alpha<\alpha^{\ddagger}\right)$ and weakly decreases economic welfare relative to an unshrouded prices equilibrium $\left(\alpha^{\dagger}<\alpha<\frac{e}{\bar{p}}\right)$. 
In terms of welfare, price discrimination represents a clear improvement relative to a shrouded prices equilibrium, because less sophisticated consumers substitute away as they get informed about the low-priced add-on. The better firms can target sophisticated consumers, the lower is the fraction of consumers substituting away and thus the higher is economic welfare. If consumer classification is perfect $(\beta=1)$, the welfare loss is zero, just as in the unshrouded prices equilibrium. If $\beta<1$, however, price discrimination decreases welfare in the case where firms would unshroud prices otherwise. The efficiency rationale for regulatory intervention then remains.

As the next proposition shows, although price discrimination can be favorable in terms of efficiency, not all consumers always gain when firms have the possibility to price discriminate.

Proposition 4 (Effects of Price Discrimination on Consumer Costs). Sophisticated consumers always gain from price discrimination, i.e., their costs of consumption are strictly lower than in a corresponding shrouded or unshrouded prices equilibrium $\left(\alpha^{\dagger}<\alpha<\alpha^{\ddagger}\right)$. Expected costs of ex-ante naive consumers decrease relative to a shrouded prices equilibrium $\left(\frac{e}{\bar{p}}<\alpha<\alpha^{\ddagger}\right)$ but increase relative to an unshrouded prices equilibrium $\left(\alpha^{\dagger}<\alpha<\frac{e}{\bar{p}}\right)$. Misclassified naive consumers always gain from price discrimination; however, those who are classified correctly face higher costs of consumption when firms price discriminate compared to an unshrouded prices equilibrium but lower compared to a shrouded prices equilibrium.

Propositions 3 and 4 are illustrated in Figure 3 (a) and (b), which documents the loss in welfare and the costs of consumption in the different price equilibria for a particular combination of parameters. In this example, firms are in an unshrouded prices equilibrium for $\alpha<\alpha^{\dagger}=0.1$ and in a shrouded prices equilibrium for $\alpha>$ $\alpha^{\ddagger}=0.37$. Without price discrimination, these regions expand until they meet at $\alpha=e / \bar{p}=0.2$. If price discrimination is possible and optimal, it replaces the other two equilibria for $0.1<\alpha<0.37$. Figure 3 (a) shows that price discrimination (dashed line) decreases the loss in welfare relative to a shrouded prices equilibrium $(0.2<\alpha<0.37)$ but increases the loss in welfare relative to an unshrouded prices equilibrium $(0.1<\alpha<0.2)$. Figure 3 (b) reveals that naive consumers who are 
classified correctly (upper dashed line) are the ones who potentially lose from price discrimination. They pay the high add-on price $\bar{p}$ whenever $\alpha>0.1$. For $0.1<$ $\alpha<0.2$ this is much more than they would pay in an otherwise unshrouded prices equilibrium. For $0.2<\alpha<0.37$ they benefit because the base good price is lower compared to the otherwise shrouded prices equilibrium due to more add-on sales to sophisticated consumers. Notably, the same consequences hold in expectation for all naive consumers (middle dashed line). Only those naive consumers who are misclassified by firms as well as sophisticated consumers (lower dashed line) gain from price discrimination.

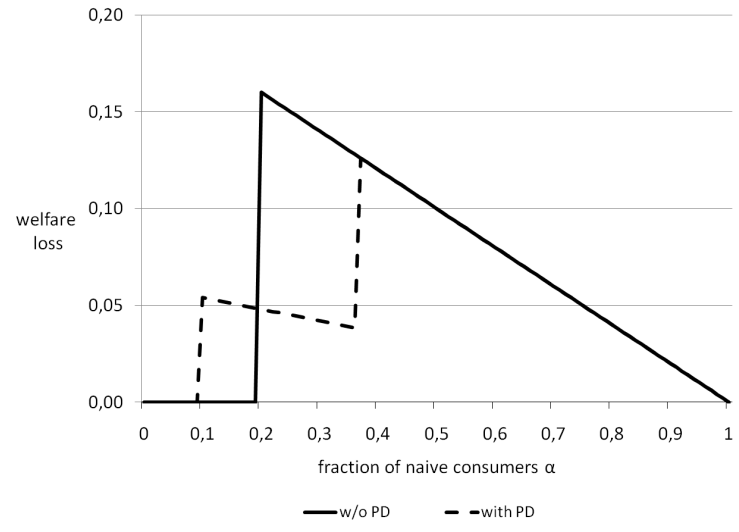

(a) Welfare

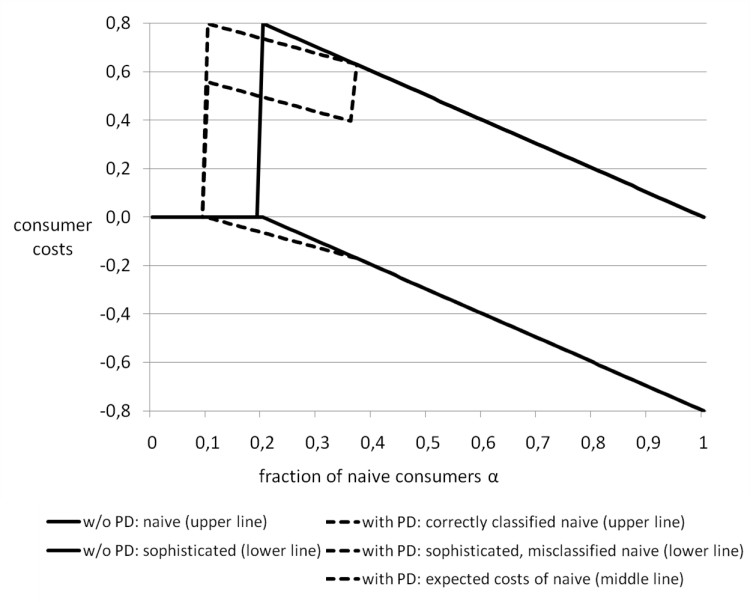

(b) Consumer Costs

Note: Parameters are $\bar{p}=1, e=0.2, \beta=\gamma=0.7$, and $\mu=0$. Resulting equilibrium thresholds are $\alpha^{\dagger}=3 / 31, e / \bar{p}=0.2$, and $\alpha^{\ddagger}=7 / 19$.

Figure 3: Welfare Effects of Price Discrimination

We next come to the welfare effects of regulatory intervention. As explained above, intervention is unnecessary if firms are in an unshrouded prices equilibrium. The main question is therefore, what effects does regulatory intervention have when firms are in a shrouded or in a price discrimination equilibrium. As the following proposition shows, increasing consumer sophistication can be beneficial but it may also do more harm than good to economic welfare.

Proposition 5 (Welfare Effects of Regulatory Intervention). Regulatory intervention has no effect on welfare if firms are in an unshrouded prices equilibrium before intervention $\left(\alpha<\alpha^{\dagger}\right)$. It has a clear positive effect on welfare only if firms are pushed 
into an unshrouded prices equilibrium after intervention $\left(\alpha^{\dagger}<\alpha<\alpha^{\S}\right)$. In all other cases, welfare effects are or can be negative. In particular, effects are either positive or negative if firms are pushed from shrouded prices towards price discrimination $\left(\alpha^{\ddagger}<\alpha<\alpha^{\sharp}\right)$. They are always negative if a shrouded prices equilibrium $\left(\alpha^{\sharp}<\alpha\right)$ or a price discrimination equilibrium $\left(\alpha^{\S}<\alpha<\alpha^{\ddagger}\right)$ remains.

Proposition 5 is illustrated in Figure 4 (a), which considers the same example as Figure 3. The solid line in panel (a) shows the welfare loss before regulatory intervention in an unshrouded prices equilibrium $(\alpha<0.1)$, a price discrimination equilibrium $(0.1<\alpha<0.37)$ and a shrouded prices equilibrium $(\alpha>0.37)$, respectively. The dashed line indicates the welfare loss in the new equilibrium situation after regulatory intervention with equilibrium thresholds equal to $\alpha^{\S}=0.16$ and $\alpha^{\sharp}=0.61$. The difference between the two lines is the net effect on welfare due to regulatory intervention. As can be seen, there are two areas, in which the effect is positive because the welfare loss is smaller after intervention than before. These are the area $0.1<\alpha<0.16$, where firms are pushed from price discrimination to unshrouded prices, and $0.37<\alpha<0.61$, where firms are in an shrouded prices equilibrium before intervention and choose price discrimination thereafter. ${ }^{11}$ In all other cases, the welfare effect is either zero $(\alpha<0.1)$ or negative $(0.16<\alpha<0.37$ or $\alpha>0.61)$. In the first case, firms unshroud the add-on price independent of whether the regulator intervenes or not. In the second and in the third case, firms adjust prices but the underlying equilibrium strategy — price discrimination and shrouded prices, respectively - remains. Because a key element of these strategies is that a fraction of or all sophisticated consumers substitute away, the effect on welfare is negative as more consumers become sophisticated due to the regulatory intervention. In other words, regulation may well be successful on an individual level, as it induces some consumers to make individually better decisions - they no longer buy the expensive add-on. However, as long as firms' pricing strategies induce these consumers to substitute away and thus behave inefficiently, regulation may fail on a social level - economic

\footnotetext{
${ }^{11}$ Note that regulatory intervention may push firms directly from a shrouded prices equilibrium to an unshrouded prices equilibrium, either if a price discrimination equilibrium does not exist or if $\lambda_{R}$ is sufficiently large such that $\alpha^{\ddagger}<\frac{1}{1-\lambda_{R}} \alpha^{\dagger}$.
} 
welfare decreases.

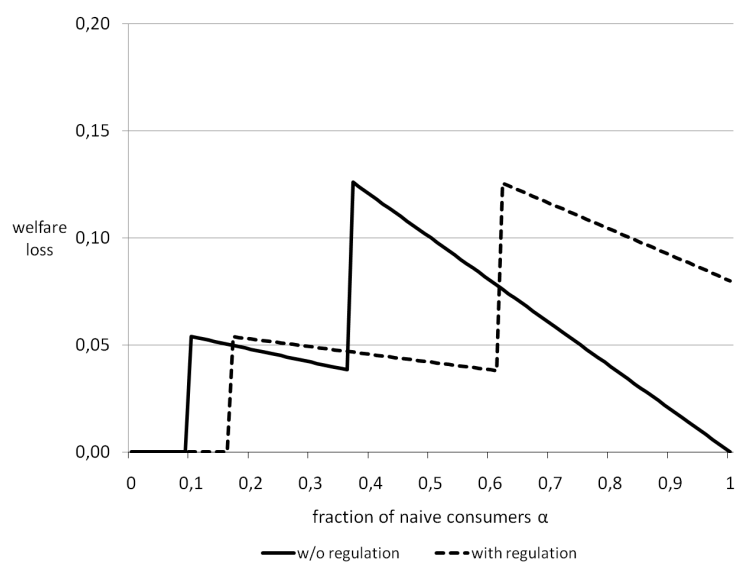

(a) Welfare

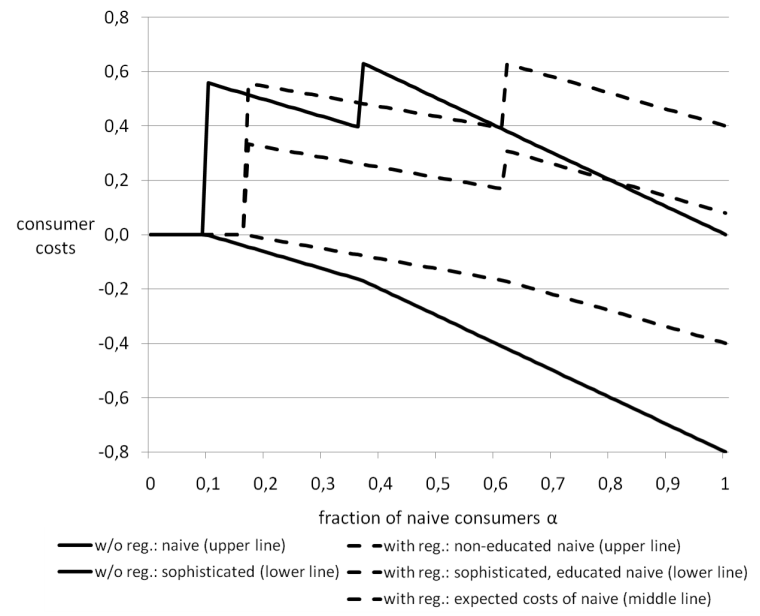

(b) Consumer Costs

Note: Parameters are $\bar{p}=1, e=0.2, \beta=\gamma=0.7, \mu=0$, and $\lambda_{R}=0.4$. Resulting equilibrium thresholds are $\alpha^{\dagger}=3 / 31, \alpha^{\S}=$ $5 / 31, e / \bar{p}=0.2, \alpha^{\ddagger}=7 / 19$ and $\alpha^{\sharp}=35 / 57$.

Figure 4: Welfare Effects of Regulatory Intervention

In this example, regulation has a positive effect on welfare if firms are pushed from shrouded prices to price discrimination. Unfortunately, this result does not hold in general. In the proof of Proposition 5 we show that the effect is negative whenever the error probability in classifying sophisticated consumers $1-\beta$ is relatively high and/or the educational effect $\lambda_{R}$ is relatively strong. The reason is the following: If the educational effect is strong, many ex-ante naive consumers become sophisticated as a result of the regulator's intervention. Firms adjust to this by switching from shrouded prices to price discrimination. Sophisticated consumers now buy the addon if and only if firms offer it to them at a low price, otherwise they substitute away. If firms target sophisticated consumers very badly, substitution may actually increase and welfare declines. ${ }^{12}$

The next proposition spells out the impact of regulatory intervention on consumer costs. The result shows that the decrease and increase in welfare goes along with different losses and gains for the different types of consumers.

\footnotetext{
${ }^{12}$ In our model, the error probability $1-\beta$ is exogenous and not affected by regulatory intervention. If $\beta$ is endogenous, it is intuitive that, if anything, regulatory intervention will increase the likelihood of misclassification because the composition of consumer groups has changed. This makes it even more likely that the welfare effect is negative.
} 
Proposition 6 (Effects of Regulatory Intervention on Consumer Costs). Regulatory intervention has zero effect on consumer costs if firms are in an unshrouded prices equilibrium before intervention $\left(\alpha<\alpha^{\dagger}\right)$. In all other cases, ex-ante naive consumers who are educated through the intervention win, i.e., they have lower consumption costs than before regulatory intervention. However, sophisticated consumers and in most cases also naive consumers who stay naive are on the losing side: their costs of consumption increase.

Figure 4 (b) illustrates how regulatory intervention affects consumer costs, as stated in Proposition 6. The same thresholds as in Figure 4 (a) apply. First, consider the solid lines that show consumer costs without regulatory intervention for sophisticated (lower line) and naive consumers (upper line). ${ }^{13}$ Second, consider the dashed lines that show consumer costs with regulatory intervention. The upper line shows the costs for consumers who are immune to education, i.e., who are naive ex ante and remain naive also if the regulator intervenes. The lower line shows consumption costs for sophisticated consumers and for ex-ante naive consumers who are educated through the intervention. The middle line shows expected costs of ex-ante naive consumers. The effect of regulatory intervention is given by the difference between the dashed and solid lines for the different types of consumers.

As the Figure illustrates, consumption costs are unaffected for $\alpha<0.1$. If $0.1<$ $\alpha<0.16$, costs of naive consumers decrease independent of whether they are actually educated by the intervention or not, since firms unshroud prices in the new equilibrium anyway. For larger $\alpha$, the effect on costs depends on whether a naive consumer is educated or not. On the one hand, ex-ante naive consumers who are educated always have lower consumption costs after regulation (lower dashed line) than before (upper solid line). Ex-ante naive consumers who remain naive, on the other hand, have higher costs after regulation (upper dashed line) than before (upper solid line), except if firms are pushed from a shrouded prices equilibrium to price discrimination $(0.31<\alpha<$ 0.61). In this case, they gain from the positive probability of being misclassified and thus being offered the low-priced add-on. Sophisticated consumers, however, lose for

\footnotetext{
${ }^{13}$ In case of price discrimination, consumption costs for naive consumers depend on whether they are classified correctly or misclassified. The Figure shows expected costs.
} 
sure: they always face higher consumption costs after regulation (lower dashed line) than before (lower solid line). Thus, while the intervention decreases the costs of the target group - ex-ante naive consumers who become educated - it simultaneously increases the costs of other consumers. Whenever the loss of the latter outweighs the gain of the former, regulatory intervention generates a negative effect on welfare.

Note that regulatory intervention can even lead to an increase in expected costs of ex-ante naive consumers alone. This happens in Figure 4 (b) if $\alpha>0.8 .^{14}$ In this case, the benefit for the educated naive consumers is already offset by the damage to those who remain naive. Thus, even a regulator who focuses exclusively on the welfare of naive consumers and neglects any impact on the sophisticated, should refrain from intervention in this case.

Our results show that regulatory intervention has a negative effect on welfare if it increases the degree of consumer sophistication, but the increase is too small to change the firms' equilibrium pricing strategy. One possible course of action the regulator may consider is to boost the educational impact of his intervention on naive consumers, i.e., increase $\lambda_{R}$. While the chances of success of such an attempt seem rather bleak in the light of the available evidence (Choi, Laibson and Madrian, 2010), Figure 5 shows that an increase in $\lambda_{R}$ may, in fact, worsen the situation in terms of welfare.

In this example, we for simplicity assume that $\beta \leq 1-\gamma$, so no price discrimination equilibrium exists. Further, parameters are chosen such that firms unshroud the add-on price if and only if $\alpha<0.2$. Starting with an ex-ante share of 70 percent naive consumers, regulatory intervention thus pushes firms from shrouded prices to an unshrouded prices equilibrium if and only if $\lambda_{R}>5 / 7$. In this case, intervention has a positive effect on welfare as it reduces the welfare loss from 0.06 before the intervention to zero afterwards. For smaller values of $\lambda_{R}$, however, regulatory intervention increases the welfare loss up to 0.16 , i.e., almost three times as high as the welfare loss before regulation. This shows that a boost in the educational effect of the intervention may in principle be a good idea, but only if the boost is strong enough.

Finally, another potential pitfall for the regulator is given by the fact that the

\footnotetext{
${ }^{14}$ The general condition is $\alpha>\max \left\{1-\frac{e}{\bar{p}}, \alpha^{\sharp}\right\}$.
} 


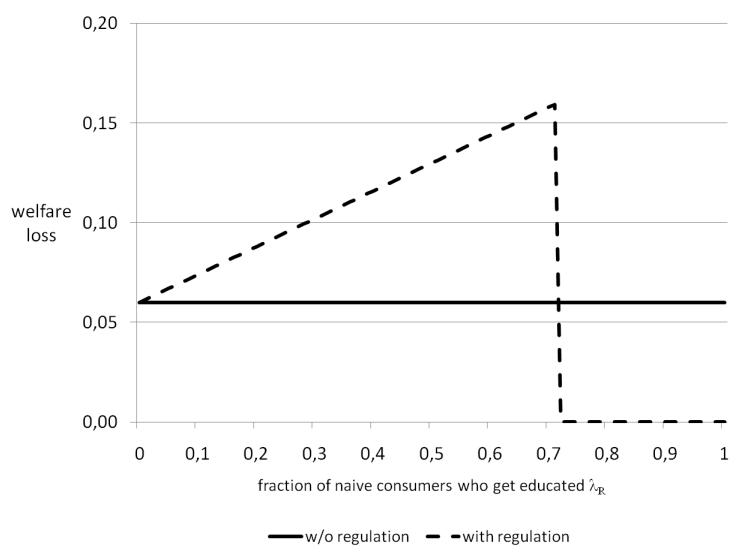

Note: Parameters are $\bar{p}=1, e=0.2, \alpha=0.7, \beta \leq 1-\gamma$.

Figure 5: Welfare Effects of an Increase in the Educational Impact $\lambda_{R}$

welfare effect of education critically depends on whether firms can price discriminate or not. If the regulator is unable to assess the pricing strategies of firms correctly, the welfare impact of regulatory intervention is thus unclear. Figure 6 illustrates such a situation. Suppose the regulator observes that firms are in a shrouded prices equilibrium and estimates the fraction of naive consumers to be $\alpha=0.5$. Educating consumers makes a fraction $\lambda_{R}=0.4$ of naive consumers informed. Figure 6 shows that the welfare effect of education is positive, i.e., the welfare loss decreases, if firms can discriminate between sophisticated and naive consumers (left panel) but is negative, i.e., the welfare loss increases, if firms are unable to do so (right panel).

\section{Alternative strategies for intervention}

The results of our analysis reveal that educating naive consumers can be a doubleedged sword and thus the wrong way for regulatory intervention in the context of addon pricing. In this section, we analyze direct, tax-funded subsidization of consumers or firms as an alternative. We consider three possible such strategies. For simplicity, we assume that firms can not engage in price discrimination and that they are in a shrouded prices equilibrium with corresponding welfare loss $(1-\alpha) e$ before regulatory intervention.

First, consider a strategy where the regulator subsidizes consumers for buying 


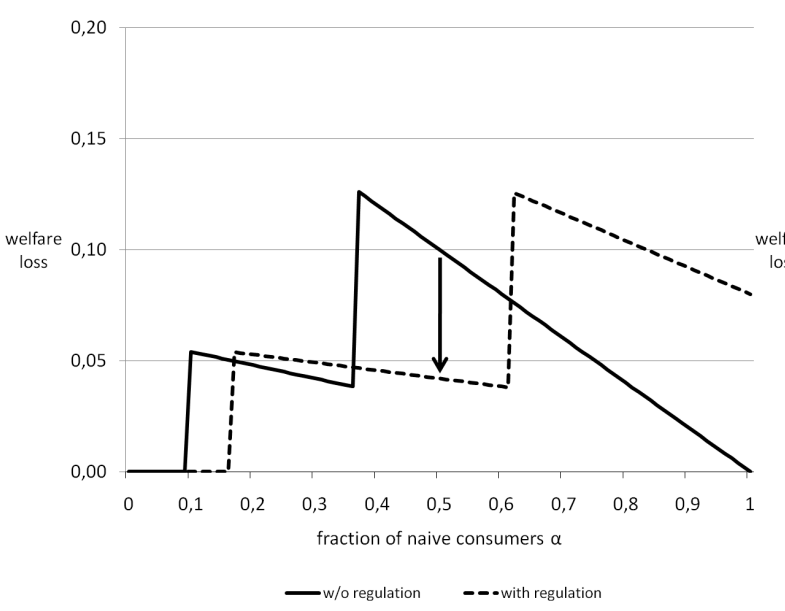

(a) welfare effects with PD

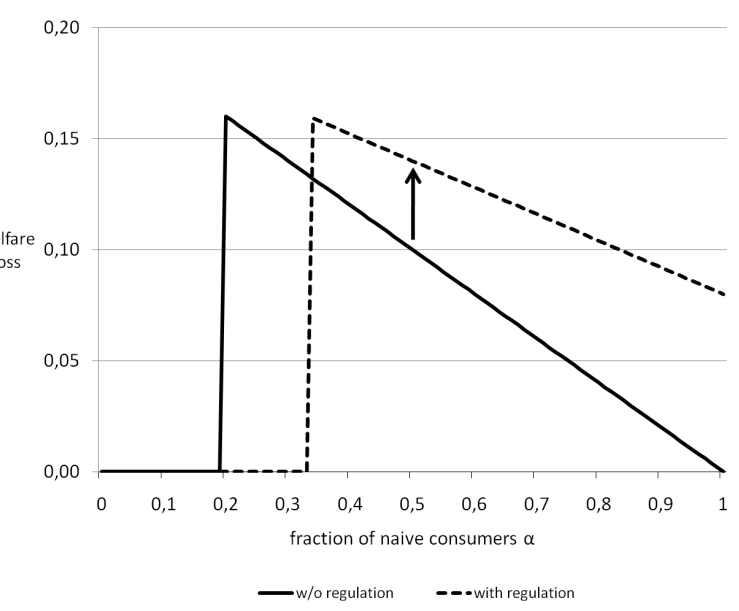

(b) welfare effects w/o PD

Note: Parameters are $\bar{p}=1, e=0.2, \beta=\gamma=0.7, \mu=0$, and $\lambda_{R}=0.4$. Resulting equilibrium thresholds are $\alpha^{\dagger}=3 / 31, \alpha^{\S}=5 / 31, e / \bar{p}=0.2, \alpha^{\ddagger}=7 / 19$ and $\alpha^{\sharp}=35 / 57$.

Figure 6: Pitfalls of the Regulator

the add-on. Such subsidy may come, for example, in the form of tax breaks. Let $\tau$ denote the subsidy offered to each consumer. Suppose for a moment that firms do not react to such a subsidy. In this case, a direct subsidy of $\tau=\bar{p}-e$ would induce all consumers to buy the add-on at price $\bar{p}$. Consumption costs of naive consumers would fall by $\tau$, while those of sophisticated consumers would be the same as before (they pay $\bar{p}-(\bar{p}-e)=e$ for the add-on which is equal to their substitution costs otherwise). Thus, the total reduction in consumer costs equals $(\bar{p}-e) \alpha$. Further, total profit of firms that now sell the add-on also to sophisticated consumers increases by $\bar{p}(1-\alpha)$. Since the total amount of subsidies is $\bar{p}-e$, the strategy seems to increase social welfare by $(\bar{p}-e) \alpha+\bar{p}(1-\alpha)-(\bar{p}-e)=(1-\alpha) e$.

Unfortunately, this scenario is unlikely to hold. Rather, firms will realize that consumers receive a subsidy for the add-on and that this increases the reservation price of naive consumers from $\bar{p}$ to $\bar{p}+\tau$. In consequence, the price of the add-on rises to $\bar{p}+\tau$, the price of the base good falls by $\alpha \tau$, and sophisticated consumers substitute away as before. The total reduction in consumer costs is equal to $\alpha \tau$, which is the same as the total amount of subsidies required. Thus, the direct effect on welfare is zero. Furthermore, the increase in naive consumers' reservation price causes $\alpha^{\dagger}$ to fall, i.e., the area where an unshrouded prices equilibrium exists becomes smaller making an efficient market outcome even less likely. Subsidizing consumers 
is therefore not a good idea.

Alternatively, the regulator may subsidize firms for implementing a particular price strategy. One obvious such possibility is to pay alls firms a subsidy $\tau=\alpha \bar{p}-e$ per consumer if they unshroud the add-on and offer it at a price $e$ to any consumers. Since firms' profits stay the same under such strategy - average revenue per consumer under the new strategy equals $p+e+(\alpha \bar{p}-e)=p+\alpha \bar{p}$ - firms are indifferent to this intervention and hence can be assumed to implement the price strategy. (Otherwise, the regulator can increase the subsidy marginally by $\epsilon$.) The effect on consumption costs is that costs of naive consumers decrease by $\bar{p}-e$. Costs of sophisticated consumers remain unchanged: they buy the add-on at the low price $e$ instead of substituting away at cost $e$. Thus, if all firms follow the desired price strategy, total costs of consumption decrease by $(\bar{p}-e) \alpha$. The required amount of subsidies which need to be funded by taxes is $\tau=\alpha \bar{p}-e$, reflecting the foregone firm profits. The net increase in welfare is $(\bar{p}-e) \alpha-(\alpha \bar{p}-e)=(1-\alpha) e$, i.e., subsidizing firms in this way reduces the welfare loss down to zero. Note that the total volume of subsidies increases in $\alpha$. The lower the share of naive consumers, the less subsidies are needed. Educating naive consumers thus decreases the costs of subsidization in this case. ${ }^{15}$

Finally, the regulator may also consider the following strategy. Suppose that in the end only firms that sell the add-on to sophisticated consumers shall receive a subsidy $\tau=\bar{p}-e$. This can be achieved by advertising the add-on at an exceptionally low price $e-\Delta$ and at the same time charging the base good at an above market price $p+\Delta$. Such strategy attracts sophisticated consumers, who now buy the add-on, but does not attract naive consumers. The market is thus split into two segments: subsidized firms that serve sophisticated consumers and non-subsidized firms that serve naive consumers. All consumers pay their reservation price for the add-on, i.e., sophisticated pay $e$ and naive pay $\bar{p}$. Average revenue per consumer is the same for all firms (including subsidies), i.e., no firm has an incentive to switch segments.

To see this, note that the market price of the base good falls by $(1-\alpha) \bar{p}$ due an equivalent increase in the average revenue per consumer made on the add-on by

\footnotetext{
${ }^{15}$ The intuition is straightforward. On the one hand, firms lose profit $\alpha(\bar{p}-e)$ on naive consumers. On the other hand, they gain profit $(1-\alpha) e$ from sophisticated profits. The net profit forgone $\alpha \bar{p}-e$ increases in the share of naive consumers.
} 
non-subsidized firms. Subsidized firms sell the base good above that market price but pass the extra revenue on to their customers by an equivalent reduction in the price of the add-on. In addition, they receive the subsidy for each consumer. Thus, average revenue per consumer at a subsidized firm equals $(p+\Delta)+(e-\Delta)+(\bar{p}-e)$ which is equal to $p+\bar{p}$, the average revenue per consumer at a non-subsidized firm.

The effect of this intervention is that costs of consumption of all consumers decrease by $(1-\alpha) \bar{p}$. The total amount of subsidies required is $(1-\alpha)(\bar{p}-e)$. The difference between both represents a net increase in welfare by $(1-\alpha) e$. Thus as before, subsidizing firms in this way reduces the welfare loss down to zero. The main difference is that in this case the required volume of subsidies decreases in $\alpha$, i.e., costs of subsidization become smaller as the share of naive consumers increases. Thus, educating naive consumers increases the costs of subsidization in this case. ${ }^{16}$

The analysis shows that the cost-efficient subsidization of firms depends on the share of naive consumers. Offering subsidies to all firms is superior if and only if the share of naive consumers is not too large $\left(\alpha<\frac{\bar{p}}{2 \bar{p}-e}\right)$. Otherwise, subsidization of firms that sell the add-on to sophisticated consumers is better as it requires a lower volume of tax-funded subsidies. Furthermore, educating naive consumers decreases the required volume of subsidies in the first case but increases subsidies in the second case. Figure 7 illustrates the situation by showing the reduction in consumer costs and the required volume of subsidies for the two subsidization strategies. While subsidies increase in $\alpha$ if all firms receive subsidies (dotted line), they decrease if subsidies are restricted to firms that serve sophisticated consumers only (dashed line).

\section{Conclusion}

When firms exploit naive consumers, educating consumers looks like a good idea. The goal is to teach naive consumers how to make better decisions; this in turn leads firms under competitive pressure to lower prices and hence increases welfare. Our results show that if consumer education is sufficiently effective such that firms unshroud

\footnotetext{
${ }^{16}$ Again, the intuition is straightforward. On the one hand, firms lose profit $(1-\alpha) \bar{p}$ on the base good. On the other hand, they gain profit $(1-\alpha) e$ from sophisticated consumers. The net profit forgone $(1-\alpha)(\bar{p}-e)$ decreases in the share of naive consumers.
} 


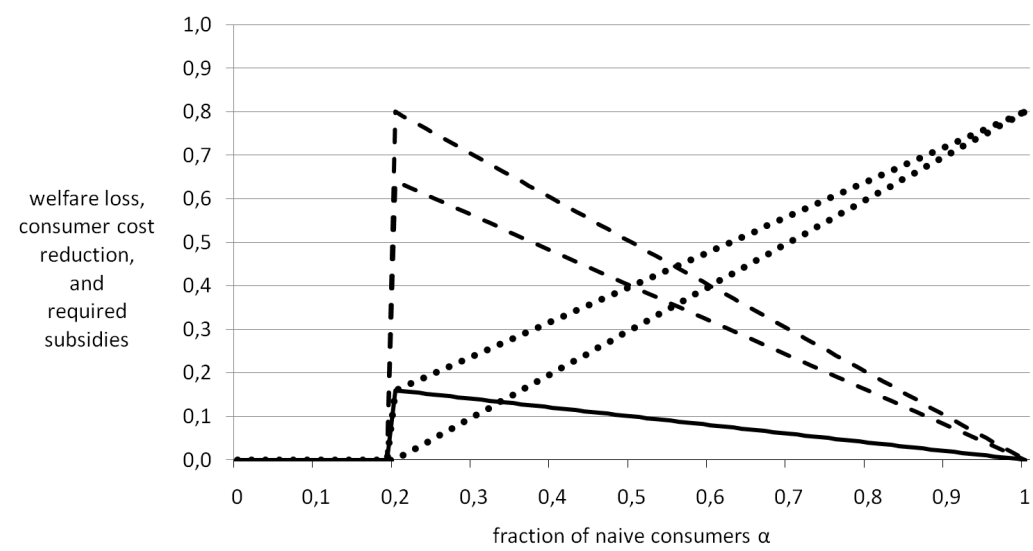

welfare loss w/o subsidies

-.- subsidies to all: consumer costs reduction (upper line)

-.. subsidies to all: required subsidies (lower line)

- -subsidies to soph.: consumer costs reduction (upper line)

- -subsidies to soph.: required subsidies (lower line)

Note: Parameters are $\bar{p}=1, e=0.2, \beta \leq 1-\gamma$. Resulting equilibrium thresholds are $\alpha^{\dagger}=\alpha^{\ddagger}=0.2$. Without subsidies, a shrouded prices equilibrium with a welfare loss of $(1-\alpha)$ e exists for $\alpha>0.2$. Both alternative regulatory strategies, "subsidies to all" and "subsidies to sophisticated only", yield a consumer cost reduction that is above the amount of required subsidies, and thus eliminate the welfare loss. "Subsidies to all" requires lower subsidies if $0.2<\alpha<0.55$ while the opposite holds for $\alpha>0.55$.

Figure 7: Welfare Effects of Alternative Regulatory Strategies

prices, economic welfare indeed increases. However, educating consumers is unlikely to be always successful because some consumers may be unreceptive to the information or simply unwilling to be told by the regulator how to decide (Agarwal et al., 2009). In this case, educating some consumers may in fact decrease economic welfare. Our results show that the welfare effects of education critically depend on the overall fraction of naive consumers, the success of consumer education, the reservation price for the add-on, substitution costs for sophisticated consumers, and the efficiency of price discrimination. Often, the regulator can only speculate about these things. As a general message our analysis suggests that regulators are advised to carefully examine consumer and firm behavior before using the seemingly harmless intervention of consumer education. Otherwise, it may be better to refrain from consumer education and to consider alternative regulatory strategies to enhance welfare. 


\section{Appendix: Proofs}

Proof of Proposition 1: The proof uses various arguments and results from GL and Caplin and Nalebuff (1991). In particular, the existence of symmetric equilibrium is guaranteed by Caplin and Nalebuff (1991). Given the specification of demand $D\left(x_{i}\right)$, equilibrium prices are determined by the first-order condition $p+\hat{p}=\frac{D(0)}{D^{\prime}(0)}=: \mu$. The latter is equal to the average profit of a firm per consumer and represents a simple parametrization of the degree of competition in the industry.

Note that if $\beta \leq 1-\gamma, \alpha^{\dagger}=\alpha^{\ddagger}=\frac{e}{\bar{p}}$. In this case, Proposition 1 is equivalent to Proposition 1 in GL (see also Corollary 1). Suppose therefore that $\beta>1-\gamma$, i.e., $\alpha^{\dagger}<\frac{e}{\bar{p}}<\alpha^{\ddagger}$.

Case 1: Suppose that $\alpha<\alpha^{\dagger}$. We show that unshrouding is an equilibrium. Suppose all firms except firm $i$ unshroud. If firm $i$ unshrouds as well, it optimally sets $\hat{p}=e$, yielding profit

$$
\begin{gathered}
(p+e)\left(1-\lambda_{F}\right) \alpha D\left(-p+p^{*}\right)+(p+e)\left(1-\left(1-\lambda_{F}\right) \alpha\right) D\left(-p-e+p^{*}+e\right) \\
=(p+e) D\left(-p+p^{*}\right) .
\end{gathered}
$$

The first term of (3) captures the profit firm $i$ makes from uninformed naive consumers, the second term captures the profit it makes from sophisticated and informed naive consumers. Solving the first-order condition yields a base good price $p=-e+\mu$.

Alternatively, firm $i$ can decide to shroud the add-on price or engage in price discrimination. GL show that shrouding is suboptimal if $\alpha<\frac{e}{\bar{p}}$, which holds in our case since $\alpha<\alpha^{\dagger} \leq \frac{e}{\bar{p}}$.

We now show that price discrimination does not exceed the profit from unshrouding, either. With price discrimination, firm $i$ optimally sets prices equal to the maximum willingness to pay of sophisticated and naive consumers, respectively, i.e., $\hat{p}_{S}=e$ and $\hat{p}_{N}=\bar{p}$. Because other firms unshroud, a fraction $\lambda_{F}$ of naive consumers become informed and behave just as sophisticated. Accordingly, price discrimination yields 
profit

$$
\begin{gathered}
(p+\bar{p})\left(1-\lambda_{F}\right) \alpha \gamma D\left(-p+p^{*}\right) \\
+p \lambda_{F} \alpha \gamma D\left(-p-e+p^{*}+e\right) \\
+(p+e)\left(1-\lambda_{F}\right) \alpha(1-\gamma) D\left(-p+p^{*}\right) \\
+(p+e) \lambda_{F} \alpha(1-\gamma) D\left(-p-e+p^{*}+e\right) \\
+(p+e)(1-\alpha) \beta D\left(-p-e+p^{*}+e\right) \\
+p(1-\alpha)(1-\beta) D\left(-p-e+p^{*}+e\right) \\
=\left(p+\bar{p}\left(1-\lambda_{F}\right) \alpha \gamma+e(\alpha(1-\gamma)+(1-\alpha) \beta)\right) D\left(-p+p^{*}\right) .
\end{gathered}
$$

The first and second term of (4) capture the profit firm $i$ makes from naive consumers who are classified correctly (which happens with ex-ante probability $\gamma$ ). On the one hand, this includes a fraction $1-\lambda_{F}$ of uninformed naive consumers who pay the high add-on price $\bar{p}$. On the other hand, this includes a fraction $\lambda_{F}$ of informed naive consumers who also get offered the high-priced add-on but substitute away. The third and fourth term represent the profit from misclassified naive consumers (which happens with ex-ante probability $1-\gamma$ ) that are offered the low add-on price and hence pay only $e$. On the one hand, this includes a fraction $1-\lambda_{F}$ of uninformed naive consumers; on the other hand, this includes a fraction $\lambda_{F}$ of informed naive consumers. The fifth term shows profits from sophisticated consumers who are classified correctly (which happens with ex-ante probability $\beta$ ) and pay $e$. Finally, the sixth term captures the profit from misclassified informed consumers who erroneously do not receive the low price offer, therefore rationally expect that $E \hat{p}=\bar{p}$ and hence substitute away.

Comparing (3) and (4) reveals that unshrouding yields strictly higher profit than 
price discrimination if and only if

$$
\begin{aligned}
e & >\bar{p}\left(1-\lambda_{F}\right) \alpha \gamma+e(\alpha(1-\gamma)+(1-\alpha) \beta) \\
e & >\bar{p}\left(1-\lambda_{F}\right) \alpha \gamma+e \alpha(1-\gamma)+e \beta-e \alpha \beta \\
e(1-\beta) & >\alpha\left(\bar{p}\left(1-\lambda_{F}\right) \gamma+e(1-\gamma)-e \beta\right) \\
\frac{e(1-\beta)}{e(1-\beta)+\left(\bar{p}\left(1-\lambda_{F}\right)-e\right) \gamma} & >\alpha,
\end{aligned}
$$

which holds as $\alpha<\alpha^{\dagger}=\min \left(\frac{e}{\bar{p}}, \frac{e(1-\beta)}{e(1-\beta)+(\bar{p}-e) \gamma}\right)$. Thus, unshrouding is an equilibrium.

Case 2: Suppose that $\alpha>\alpha^{\ddagger}$. We show that an equilibrium exists, in which all firms shroud the add-on price. Suppose all firms except firm $i$ shroud. If firm $i$ shrouds as well, it optimally sets $\hat{p}=\bar{p}$, yielding profit

$$
\begin{gathered}
(p+\bar{p}) \alpha D\left(-p+p^{*}\right)+p(1-\alpha) D\left(-p-e+p^{*}+e\right) \\
=(p+\alpha \bar{p}) D\left(-p+p^{*}\right) .
\end{gathered}
$$

The first term of (5) captures the profit from naive consumers who buy the add-on at the high price $\bar{p}$. The second term captures the profit from sophisticated consumers who rationally expect the add-on to be priced at $E \hat{p}=\bar{p}$ and hence substitute away.

Again, we can use results from GL who show that unshrouding leads to lower profit if $\alpha>\frac{e}{\bar{p}}$, which holds in our case as $\alpha>\alpha^{\ddagger} \geq \frac{e}{\bar{p}}$. It thus again remains to be shown that price discrimination does not increase profit, either.

If all firms shroud, all naive consumers are uninformed unless they are misclassified by firm $i$ and erroneously get informed about the add-on. Hence, the profit from price 
discrimination is equal to:

$$
\begin{gathered}
(p+\bar{p}) \alpha \gamma D\left(-p+p^{*}\right) \\
+(p+e) \alpha(1-\gamma)\left(1-\lambda_{F}\right) D\left(-p+p^{*}\right) \\
+(p+e) \alpha(1-\gamma) \lambda_{F} D\left(-p-e+p^{*}+e\right) \\
+(p+e)(1-\alpha) \beta D\left(-p-e+p^{*}+e\right) \\
+p(1-\alpha)(1-\beta) D\left(-p-e+p^{*}+e\right) \\
=(p+\alpha \gamma \bar{p}+e(\alpha(1-\gamma)+(1-\alpha) \beta)) D\left(-p+p^{*}\right) .
\end{gathered}
$$

The first term of (6) captures the profit firm $i$ makes from naive consumers who are classified correctly and hence pay the high add-on price $\bar{p}$. The second and third term capture the profit from naive consumers who are misclassified (which happens with ex-ante probability $1-\gamma$ ). These consumers are offered the low add-on price and hence pay only $e$. A fraction $\left(1-\lambda_{F}\right)$ of these consumers stays uninformed while a fraction $\lambda_{F}$ becomes informed. The fourth term captures the profit from sophisticated consumers who are classified correctly (which happens with ex-ante probability $\beta$ ). The fifth term captures the profit from misclassified sophisticated consumers who erroneously do not receive the low price offer, therefore rationally expect that $E \hat{p}=\bar{p}$ and hence substitute away.

Comparing (5) and (6) reveals that shrouding yields strictly higher profit than price discrimination if and only if

$$
\begin{aligned}
\alpha \bar{p} & >\alpha \gamma \bar{p}+e(\alpha(1-\gamma)+(1-\alpha) \beta) \\
\alpha \bar{p} & >\alpha(e-e \gamma-e \beta+\bar{p} \gamma)+\beta e \\
\alpha(\bar{p}-e+e \gamma+e \beta-\bar{p} \gamma) & >\beta e \\
\alpha(e \beta+(\bar{p}-e)(1-\gamma)) & >\beta e \\
\alpha & >\frac{\beta e}{e \beta+(\bar{p}-e)(1-\gamma)} \\
\alpha & >\alpha^{\ddagger} .
\end{aligned}
$$

Thus, shrouding is an equilibrium. 
Case 3: Finally, suppose $\alpha^{\dagger}<\alpha<\alpha^{\ddagger}$. We show that price discrimination is an equilibrium. Suppose all other firms engage in price discrimination. If firm $i$ price discriminates, as well, it makes profit

$$
(p+\alpha \gamma \bar{p}+e(\alpha(1-\gamma)+(1-\alpha) \beta)) D\left(-p+p^{*}\right)
$$

equivalent to Equation (6). ${ }^{17}$

Alternatively, if firm $i$ shrouds, profit is equal to

$$
\begin{gathered}
(p+\bar{p}) \alpha \gamma D\left(-p+p^{*}\right) \\
+(p+\bar{p}) \alpha(1-\gamma)\left(1-\lambda_{F}\right) D\left(-p+p^{*}\right) \\
+p \alpha(1-\gamma) \lambda_{F} D\left(-p-e+p^{*}+e\right) \\
+p(1-\alpha) D\left(-p-e+p^{*}+e\right) \\
=\left(p+\bar{p} \alpha\left(\gamma+(1-\gamma)\left(1-\lambda_{F}\right)\right)\right) D\left(-p+p^{*}\right) .
\end{gathered}
$$

The first term of (8) captures the profit firm $i$ makes from uninformed naive consumers who are classified correctly (by all other firms who price discriminate) and hence pay the high add-on price $\bar{p}$. The second and third term capture the profit from naive consumers who are misclassified (by all other firms who price discriminate). A fraction $\left(1-\lambda_{F}\right)$ of these consumers stays uninformed and also pays the high add-on price $\bar{p}$ (second term). A fraction $\lambda_{F}$ becomes informed and substitutes away (third term). The fourth term captures the profit from sophisticated consumers who substitute away (or buy the low-priced add-on from a competitor).

Comparing (7) and (8) reveals that price discrimination yields strictly higher profit

\footnotetext{
${ }^{17} \mathrm{We}$ assume that all firms follow the same classification of consumers.
} 
than shrouding if and only if

$$
\begin{aligned}
\alpha \gamma \bar{p}+e(\alpha(1-\gamma)+(1-\alpha) \beta) & >\bar{p} \alpha\left(\gamma+(1-\gamma)\left(1-\lambda_{F}\right)\right) \\
\beta e+\alpha(\gamma \bar{p}+e-e \gamma-e \beta) & >\alpha\left(\bar{p} \gamma+\bar{p}(1-\gamma)\left(1-\lambda_{F}\right)\right) \\
\beta e & \left.>\alpha\left(\bar{p} \gamma+\bar{p}(1-\gamma)\left(1-\lambda_{F}\right)-e+e \gamma+e \beta-\bar{p} \gamma\right)\right) \\
\beta e & >\alpha\left(e \beta+\bar{p}(1-\gamma)\left(1-\lambda_{F}\right)-e(1-\gamma)\right) \\
\beta e & >\alpha\left(e \beta+\left(\bar{p}-\bar{p} \lambda_{F}-e\right)(1-\gamma)\right) \\
\frac{\beta e}{e \beta+\left(\bar{p}\left(1-\lambda_{F}\right)-e\right)(1-\gamma)} & >\alpha,
\end{aligned}
$$

which holds as $\alpha<\alpha^{\ddagger}=\max \left(\frac{e}{\bar{p}}, \frac{e \beta}{e \beta+(\bar{p}-e)(1-\gamma)}\right)$.

Furthermore, profit from unshrouding is equal to

$$
(p+e) D\left(-p+p^{*}\right)
$$

equivalent to Equation (3). Comparing (7) and (9) reveals that price discrimination yields strictly higher profit than unshrouding if and only if

$$
\begin{aligned}
\alpha \gamma \bar{p}+e(\alpha(1-\gamma)+(1-\alpha) \beta) & >e \\
\alpha(\gamma \bar{p}+e-e \gamma-e \beta) & >e-e \beta \\
\alpha & >\frac{e(1-\beta)}{e(1-\beta)+(\bar{p}-e) \gamma} \\
\alpha & >\alpha^{\dagger} .
\end{aligned}
$$

Thus, price discrimination is an equilibrium.

Q.E.D.

Proof of Proposition 2: Denote $\tilde{\alpha}:=\left(1-\lambda_{R}\right) \alpha$ the fraction of naive consumers after regulatory intervention. The result follows from Proposition 1 replacing $\alpha$ by $\tilde{\alpha}$. Q.E.D.

Proof of Proposition 3: Consider Table 1. In an unshrouded prices equilibrium, all consumers buy the add-on; hence the welfare loss is zero. In a price discrimination equilibrium, the fraction of sophisticated consumers who substitute away is equal to 
$(1-\beta)(1-\alpha)$. In a shrouded prices equilibrium, this fraction is equal to $1-\alpha$. Q.E.D.

Proof of Proposition 4: Sophisticated consumers either buy the add-on at price $e$ or exert substitution costs of the same amount. Thus, total costs of consumption of sophisticated consumers depend on the price of the base good. Generally, if price discrimination is possible, i.e., $\alpha^{\dagger}<\frac{e}{\bar{p}}<\alpha^{\ddagger}$, the price of the base good equals

$$
\mu-\alpha \gamma \bar{p}-e(\alpha(1-\gamma)+(1-\alpha) \beta)
$$

for $\alpha^{\dagger}<\alpha<\alpha^{\ddagger}$. If price discrimination is not possible, an unshrouded prices equilibrium exists for $\alpha^{\dagger}<\alpha<\frac{e}{\bar{p}}$ with a base good price equal to $\mu-e$. Since $\alpha>\alpha^{\dagger}$, the former price is lower than the latter price. Similarly, for $\frac{e}{\bar{p}}<\alpha<\alpha^{\ddagger}$ a shrouded prices equilibrium exists if price discrimination is not possible. In this case, the base good price equals $\mu-\alpha \bar{p}$. Again, since $\alpha<\alpha^{\ddagger}$, the former price is lower than the latter price. This proves the first statement.

Next, consider prices of naive consumers. If price discrimination is not possible, naive consumers pay a total price of $\mu-e+e=\mu$ in an unshrouded prices equilibrium $\left(\alpha<\frac{e}{\bar{p}}\right)$ and a total price of $\mu-\alpha \bar{p}+\bar{p}=\mu+(1-\alpha) \bar{p}$ in a shrouded prices equilibrium $\left(\frac{e}{\bar{p}}<\alpha\right)$. If price discrimination is possible $\left(\alpha^{\dagger}<\alpha<\alpha^{\ddagger}\right)$, naive consumers who are correctly classified (with probability $\gamma$ ) buy the add-on at $p_{N}=\bar{p}$, and naive consumers who are misclassified (with probability $1-\gamma$ ) buy the add-on at $p_{S}=e$. The expected total price for naive consumers is equal to

$$
\begin{gathered}
\mu-\alpha \gamma \bar{p}-e(\alpha(1-\gamma)+(1-\alpha) \beta)+\gamma \bar{p}+(1-\gamma) e \\
=\mu+(1-\alpha)(\gamma \bar{p}+e(1-\gamma)-e \beta) .
\end{gathered}
$$

Since $e<\bar{p}$ and $\beta<1$, it immediately follows that this price is higher than $\mu$ (unshrouded prices equilibrium) but lower than $\mu+(1-\alpha) \bar{p}$ (shrouded prices equilibrium). This proves the second statement.

In a price discrimination equilibrium $\left(\alpha^{\dagger}<\alpha<\alpha^{\ddagger}\right)$, naive consumers who are 
misclassified pay a total price

$$
\mu-\alpha \gamma \bar{p}-e(\alpha(1-\gamma)+(1-\alpha) \beta)+e
$$

Since $\alpha^{\dagger}<\alpha$, this price is lower than $\mu$ (unshrouded prices equilibrium), and consequently also lower than $\mu+(1-\alpha) \bar{p}$ (shrouded prices equilibrium). This proves the third statement.

Finally, in a price discrimination equilibrium $\left(\alpha^{\dagger}<\alpha<\alpha^{\ddagger}\right)$, naive consumers that are correctly classified pay a total price

$$
\begin{aligned}
\mu & -\alpha \gamma \bar{p}-e(\alpha(1-\gamma)+(1-\alpha) \beta)+\bar{p} \\
& =\mu-\alpha \gamma \bar{p}-e \alpha(1-\gamma)-e(1-\alpha) \beta+\alpha \bar{p}+(1-\alpha) \bar{p} \\
& =\mu+\alpha(1-\gamma)(\bar{p}-e)+(1-\alpha)(\bar{p}-e \beta) .
\end{aligned}
$$

Since $e<\bar{p}$ and $\beta<1$, it immediately follows that this price is higher than $\mu$ (unshrouded prices equilibrium). Since $\alpha<\alpha^{\ddagger}$, this price is lower than $\mu+(1-\alpha) \bar{p}$ (shrouded prices equilibrium). This proves the last statement.

Q.E.D.

Proof of Proposition 5: Consider Table 1. If an unshrouded prices equilibrium exists with and without regulatory intervention $\left(\alpha<\alpha^{\dagger}\right)$, the welfare loss is always zero. This proves the first statement.

If firms are pushed from price discrimination to an unshrouded prices equilibrium $\left(\alpha^{\dagger}<\alpha<\alpha^{\S}\right)$, the welfare loss falls from $(1-\beta)(1-\alpha) e$ to zero. This proves the second statement.

The third statement summarizes the results for the remaining cases. If firms are pushed from shrouded prices to price discrimination $\left(\alpha^{\ddagger}<\alpha<\alpha^{\sharp}\right)$, the welfare loss changes from $(1-\alpha) e$ to $(1-\beta)\left(1-\left(1-\lambda_{R}\right) \alpha\right) e$. Accordingly, the net effect of 
regulatory intervention is positive if and only if

$$
\begin{aligned}
(1-\alpha) e & >(1-\beta)\left(1-\left(1-\lambda_{R}\right) \alpha\right) e \\
(1-\alpha) e & >\left(1-\left(1-\lambda_{R}\right) \alpha\right) e-\beta\left(1-\left(1-\lambda_{R}\right) \alpha\right) e \\
0 & >\lambda_{R} \alpha e-\beta\left(1-\left(1-\lambda_{R}\right) \alpha\right) e \\
\beta\left(1-\left(1-\lambda_{R}\right) \alpha\right) e & >\lambda_{R} \alpha e \\
\beta & >\frac{\lambda_{R} \alpha}{1-\left(1-\lambda_{R}\right) \alpha} .
\end{aligned}
$$

Depending on $\beta, \lambda_{R}$ and $\alpha$, this condition may or may not hold. This proves the fourth statement.

Finally, if a shrouded prices equilibrium exists without and with regulatory intervention $\left(\alpha^{\sharp}<\alpha\right)$, the welfare loss is $(1-\alpha) e$ and $\left(1-\left(1-\lambda_{R}\right) \alpha\right) e$, respectively. Thus, welfare decreases by $\lambda_{R} \alpha e$ through regulatory intervention. Similarly, if a price discrimination equilibrium exists without and with regulatory intervention $\left(\alpha^{\S}<\alpha<\right.$ $\left.\alpha^{\ddagger}\right)$, the loss is equal to $(1-\beta)(1-\alpha) e$ and $(1-\beta)\left(1-\left(1-\lambda_{R}\right) \alpha\right) e$, respectively. Thus, welfare decreases by $(1-\beta) \lambda_{R} \alpha e$ in this case. This proves the last statement.

Q.E.D.

Proof of Proposition 6: If an unshrouding equilibrium exists with and without intervention $\left(\alpha<\alpha^{\dagger}\right)$, all consumers face the same costs of consumption $\mu$. Thus, regulatory intervention has no effect. This proves the first statement.

In all other cases, expected consumer costs change through regulatory intervention. Consider first the sophisticated. Their costs of consumption solely depend on the price of the base good, which is $\mu-e$ in an unshrouded prices equilibrium, $\mu-\alpha \bar{p}$ in a shrouded prices equilibrium, and

$$
\mu-\alpha \gamma \bar{p}-e(\alpha(1-\gamma)+(1-\alpha) \beta)=\mu-\alpha(\gamma \bar{p}+e(1-\gamma)-e \beta)-e \beta
$$

in a price discrimination equilibrium (always before regulatory intervention). It can easily be seen that, if regulatory intervention lowers the fraction of naive consumers from $\alpha$ to $\left(1-\lambda_{R}\right) \alpha$, the price of the base good in a price discrimination or shrouded 
prices equilibrium increases. Further, if firms are pushed from a shrouded prices to a price discrimination equilibrium or from a price discrimination to an unshrouded prices equilibrium, the price of the base good increases as well, since $\mu-\alpha \bar{p}<$ $\mu-\alpha(\gamma \bar{p}+e(1-\gamma)-e \beta)-e \beta$ if $\alpha^{\ddagger}<\alpha<\alpha^{\sharp}$ and $\mu-\alpha(\gamma \bar{p}+e(1-\gamma)-e \beta)-e \beta<\mu-e$ if $\alpha^{\dagger}<\alpha<\alpha^{\S}$. Hence, consumption costs of sophisticated consumers always increase.

With regard to ex-ante naive consumers, consumption costs depend on whether a naive consumer becomes informed through education (with probability $\lambda_{R}$ ) or remains uninformed (with probability $1-\lambda_{R}$ ). Consider first ex-ante naive consumers who remain uninformed. Just like the sophisticated, these consumers always pay a higher base good price. Since they remain naive, their costs on the add-on are unchanged except if firms are pushed from a shrouded prices to a price discrimination equilibrium. In this case, they are misclassified with positive probability wich may lower their consumption costs. In particular, their costs decrease if $\alpha^{\ddagger}<\alpha<\alpha^{\sharp}$ and $\mu-\alpha \bar{p}+\bar{p}$ is larger than

$$
\begin{gathered}
\mu-\left(1-\lambda_{R}\right) \alpha \gamma \bar{p}-e\left(\left(1-\lambda_{R}\right) \alpha(1-\gamma)+\left(1-\left(1-\lambda_{R}\right) \alpha\right) \beta\right)+\gamma \bar{p}+(1-\gamma) e \\
=\mu+\left(1-\left(1-\lambda_{R}\right) \alpha\right)(\gamma \bar{p}+e(1-\gamma)-e \beta),
\end{gathered}
$$

which holds if $\lambda_{R}$ is sufficiently small (cf. the proof of Proposition 4).

Consider next the ex-ante naive consumers who become informed. These consumers pay a higher based good price just as all other consumers, but always save on the add-on. We consider all possible cases separately.

1) If firms are pushed from price discrimination to unshrouded prices $\left(\alpha^{\dagger}<\alpha<\right.$ $\left.\alpha^{\S}\right)$, consumption costs change from

$$
\begin{gathered}
\mu-\alpha \gamma \bar{p}-e(\alpha(1-\gamma)+(1-\alpha) \beta)+\gamma \bar{p}+(1-\gamma) e \\
=\mu+(1-\alpha)(\gamma \bar{p}+e(1-\gamma)-e \beta)
\end{gathered}
$$

to $\mu$, which constitutes a decline since $e<\bar{p}$.

2) If a price discrimination equilibrium exists with and without intervention $\left(\alpha^{\S}<\right.$ 
$\left.\alpha<\alpha^{\ddagger}\right)$, costs change from

$$
\mu-\alpha \gamma \bar{p}-e(\alpha(1-\gamma)+(1-\alpha) \beta)+\gamma \bar{p}+(1-\gamma) e
$$

to

$$
\mu-\left(1-\lambda_{R}\right) \alpha \gamma \bar{p}-e\left(\left(1-\lambda_{R}\right) \alpha(1-\gamma)+\left(1-\left(1-\lambda_{R}\right) \alpha\right) \beta\right)+e .
$$

Thus, regulatory intervention decreases consumption costs, if and only if

$$
\begin{aligned}
& \mu-\left(1-\lambda_{R}\right) \alpha \gamma \bar{p}-e\left(\left(1-\lambda_{R}\right) \alpha(1-\gamma)+\left(1-\left(1-\lambda_{R}\right) \alpha\right) \beta\right)+e \\
&<\mu-\alpha \gamma \bar{p}-e(\alpha(1-\gamma)+(1-\alpha) \beta)+\gamma \bar{p}+(1-\gamma) e \\
& \lambda_{R} \alpha \gamma \bar{p}+e \lambda_{R} \alpha(1-\gamma)-e \lambda_{R} \alpha \beta+e<\gamma \bar{p}+(1-\gamma) e \\
& \alpha \lambda_{R}(\gamma \bar{p}+e-\gamma e-e \beta)<(\bar{p}-e) \gamma \\
& \alpha<\frac{1}{\lambda_{R}} \frac{(\bar{p}-e) \gamma}{e(1-\beta)+(\bar{p}-e) \gamma} .
\end{aligned}
$$

Since the right hand side is larger than one (which can easily be derived from the fact that $\left.\alpha^{\S}<1\right)$, the condition is fulfilled for all $\alpha$.

3) If firms are pushed from shrouded prices to price discrimination $\left(\alpha^{\ddagger}<\alpha<\alpha^{\sharp}\right)$, costs change from $\mu+(1-\alpha) \bar{p}$ to

$$
\mu-\left(1-\lambda_{R}\right) \alpha \gamma \bar{p}-e\left(\left(1-\lambda_{R}\right) \alpha(1-\gamma)+\left(1-\left(1-\lambda_{R}\right) \alpha\right) \beta\right)+e .
$$

Thus, regulatory intervention decreases consumption costs, if and only if

$$
\begin{gathered}
\mu-\left(1-\lambda_{R}\right) \alpha \gamma \bar{p}-e\left(\left(1-\lambda_{R}\right) \alpha(1-\gamma)+\left(1-\left(1-\lambda_{R}\right) \alpha\right) \beta\right)+e<\mu+(1-\alpha) \bar{p} \\
-\left(1-\lambda_{R}\right) \alpha \gamma \bar{p}-e\left(1-\lambda_{R}\right) \alpha(1-\gamma)+e\left(1-\lambda_{R}\right) \alpha \beta+\alpha \bar{p}<\bar{p}+e \beta-e \\
\alpha<\frac{\bar{p}+e \beta-e}{\bar{p}+e \beta-\left(\gamma \bar{p}+(1-\gamma) e-\lambda_{R}(e(1-\beta)+(\bar{p}-e) \gamma)\right)} .
\end{gathered}
$$

By the same argument as before the right hand side is larger than one, so the condition is fulfilled for all $\alpha$.

4) Finally, if a shrouded prices equilibrium exists with and without regulatory intervention $\left(\alpha^{\sharp}<\alpha\right)$, costs change from $\mu+(1-\alpha) \bar{p}$ to $\mu-\left(1-\lambda_{R}\right) \alpha \bar{p}+e$. Thus, 
regulatory intervention decreases costs, if and only if

$$
\begin{aligned}
\mu-\left(1-\lambda_{R}\right) \alpha \bar{p}+e & <\mu+(1-\alpha) \bar{p} \\
-\alpha \bar{p}+\lambda_{R} \alpha \bar{p}+e & <\bar{p}-\alpha \bar{p} \\
\alpha & <\frac{1}{\lambda_{R}}\left(1-\frac{e}{\bar{p}}\right) .
\end{aligned}
$$

Again, the right hand side is larger than one, because $\alpha^{\sharp}<1$. Thus, costs decrease. Q.E.D. 


\section{References}

Agarwal, Sumit, Gene Amromin, Itzhak Ben-David, Souphala Chomsisengphet, and Douglas D. Evanoff. 2009. "Do Financial Counseling Mandates Improve Mortgage Choice and Performance? Evidence from a Legislative Experiment." Federal Reserve Bank of Chicago Working Paper 2009-07.

Anderson, Simon P., André de Palma, and Jacques-François Thisse. 1992. Discrete Choice Theory of Product Differentiation. Cambridge, MA: MIT Press.

Armstrong, Mark. 2008. "Interactions between Competition and Consumer Policy." Competition Policy International, 4(1): 97-147.

Armstrong, Mark, John Vickers, and Jidong Zhou. 2009. "Consumer Protection and the Incentive to Become Informed." Journal of the European Economic Association, 7(2-3): 399-410.

Bhattacharya, Utpal, Andreas Hackethal, Simon Kaesler, Benjamin Loos, and Steffen Meyer. 2011. "Is Unbiased Financial Advice To Retail Investors Sufficient? Answers from a Large Field Study." Review of Financial Studies, forthcoming.

Calvet, Laurent E., John Y. Campbell, and Paolo Sodini. 2009. "Measuring the Financial Sophistication of Households." American Economic Review, 99(2): 393-98.

Caplin, Andrew, and Barry Nalebuff. 1991. "Aggregation and Imperfect Competition: On the Existence of Equilibrium." Econometrica, 59(1): 25-59.

Carlin, Bruce I. 2009. "Strategic Price Complexity in Retail Financial Markets." Journal of Financial Economics, 91(3): 278 - 287.

Choi, James, David Laibson, and Brigitte C. Madrian. 2010. "Why Does the Law Of One Price Fail? An Experiment on Index Mutual Funds." Review of Financial Studies, 23(4): 1405-1432. 
DellaVigna, Stefano. 2009. "Psychology and Economics: Evidence from the Field." Journal of Economic Literature, 47(2): 315-372.

De Meza, David, Bernd Irlenbusch, and Diane Reyniers. 2008. "Financial Capability: A Behavioural Economics Perspective." Consumer Research 69, Financial Services Authority, UK.

Ellison, Glenn. 2006. "Bounded Rationality in Industrial Organization." In Advances in Economics and Econometrics: Theory and Applications, Ninth World Congress. Vol. 2, 142-74. Cambridge, UK: Cambridge University Press.

Gabaix, Xavier, and David Laibson. 2006. "Shrouded Attributes, Consumer Myopia, and Information Suppression in Competitive Markets." Quarterly Journal of Economics, 121(2): 505-540.

Glaeser, Edward L., and Gergely Ujhelyi. 2010. "Regulating Misinformation." Journal of Public Economics, 94(3-4): 247-257.

Henderson, Brian J., and Neil D. Pearson. 2011. "The Dark Side of Financial Innovation: A Case Study of the Pricing of a Retail Financial Product." Journal of Financial Economics, 100(2): 227-247.

Jolls, Christine, and Cass R. Sunstein. 2006. "Debiasing through Law." Journal of Legal Studies, 35: 199-241.

Kamenica, Emir, Sendhil Mullainathan, and Richard Thaler. 2011. "Helping Consumers Know Themselves." American Economic Review, 101(3): 417-22.

Lacko, James M., and Janis K. Pappalardo. 2010. "The Failure and Promise of Mandated Consumer Mortgage Disclosures: Evidence from Qualitative Interviews and a Controlled Experiment with Mortgage Borrowers." American Economic Review, 100(2): 516-21.

Lal, Rajiv, and Carmen Matutes. 1994. "Retail Pricing and Advertising Strategies." Journal of Business, 67: 345-370. 
OECD. 2009. "Financial Literacy and Consumer Protection: Overlooked Aspects of the Crisis." OECD Recommendation on Good Practices on Financial Education and Awareness Relating to Credit.

Spiegler, Ran. 2006a. "Competition over Agents with Boundedly Rational Expectations." Theoretical Economics, 1(2): 207-231.

Spiegler, Ran. 2006b. "The Market for Quacks." Review of Economic Studies, 73(4): 1113-1131.

Spiegler, Ran. 2011. Bounded rationality and industrial organization. New York, NY: Oxford University Press.

Willis, Lauren E. 2011. "The Financial Education Fallacy." American Economic Review, 101(3): 429-34.

Woodward, Susan E., and Robert E. Hall. 2010. "Consumer Confusion in the Mortgage Market: Evidence of Less Than a Perfectly Transparent and Competitive Market." American Economic Review, 100(2): 511-15. 